\title{
Emerging trends in colorectal cancer: Dysregulated signaling pathways (Review)
}

\author{
REHAN AHMAD ${ }^{1 *}$, JAIKEE KUMAR SINGH $^{2 *}$, AMOOLYA WUNNAVA $^{2}$, \\ OMAR AL-OBEED $^{1}$, MAHA ABDULLA ${ }^{1}$ and SANDEEP KUMAR SRIVASTAVA ${ }^{2}$ \\ ${ }^{1}$ Colorectal Research Chair, Department of Surgery, King Saud University College of Medicine, \\ Riyadh 11472, Saudi Arabia; ${ }^{2}$ Department of Biosciences, Manipal University Jaipur, Jaipur, Rajasthan 303007, India
}

Received October 16, 2020; Accepted December 14, 2020

DOI: $10.3892 /$ ijmm.2021.4847

\begin{abstract}
Colorectal cancer (CRC) is the third most frequently detected type of cancer, and the second most common cause of cancer-related mortality globally. The American Cancer Society predicted that approximately 147,950 individuals would be diagnosed with CRC, out of which 53,200 individuals would succumb to the disease in the USA alone in 2020. CRC-related mortality ranks third among both males and females in the USA. CRC arises from 3 major pathways: i) The adenoma-carcinoma sequence; ii) serrated pathway; and iii) the inflammatory pathway. The majority of cases of CRC are sporadic and result from risk factors, such as a sedentary lifestyle, obesity, processed diets, alcohol consumption and smoking. CRC is also a common preventable cancer. With widespread CRC screening, the incidence and mortality from CRC have decreased in developed countries. However, over the past few decades, CRC cases and mortality have been on the rise in young adults (age, $<50$ years). In addition, CRC cases are increasing in developing countries with a low gross domestic product (GDP) due to lifestyle changes. CRC is an etiologically heterogeneous disease classified by tumor location and alterations in global gene expression. Accumulating genetic and epigenetic perturbations and aberrations over time in tumor suppressor genes, oncogenes and DNA mismatch repair genes could be a precursor to the onset of colorectal cancer. CRC can be divided as sporadic, familial, and inherited depending on the origin of the mutation. Germline mutations in APC and MLH1 have been proven to play an etiological role, resulting in the predisposition of individuals to CRC. Genetic alterations cause the dysregulation of signaling pathways
\end{abstract}

Correspondence to: Dr Sandeep Kumar Srivastava, Department of Biosciences, Manipal University Jaipur, Dehmi Kalan, Jaipur-Ajmer Express Highway, Jaipur, Rajasthan 303007, India

E-mail: sandeepkumar.srivastava@jaipur.manipal.edu

${ }^{*}$ Contributed equally

Key words: colorectal cancer, signaling pathways, mutations, metastasis, targeted therapy leading to drug resistance, the inhibition of apoptosis and the induction of proliferation, invasion and migration, resulting in CRC development and metastasis. Timely detection and effective precision therapies based on the present knowledge of CRC is essential for successful treatment and patient survival. The present review presents the CRC incidence, risk factors, dysregulated signaling pathways and targeted therapies.

\section{Contents}

1. Introduction

2. Incidence of colorectal cancer

3 . Types of colorectal cancer

4. Mutation basis and occurrence of colorectal cancer

5. Molecular pathways of colorectal cancer

6. Risk factors

7. Overview of dysregulated signaling pathways

8. Crosstalk among various pathways

9. Current chemotherapeutics for colorectal cancer

10. Strategies for the targeted therapy of colorectal cancer 11. Conclusions

\section{Introduction}

Based on GLOBOCAN 2018 statistics, colorectal cancer (CRC) ranks as the third most frequently detected cancer and the second prominent cancer-related fatality worldwide despite the advent of better screening for early detection and therapeutic advances (1). By the year 2030, the incidence of CRC is predicted to increase by $60 \%$ in developing countries (2). Adenocarcinomas constitute $>90 \%$ of CRC cases developing as a malignant lesion in glandular epithelial cells of the large intestine comprising of the colon and rectum (3). The majority of CRC cases (60-65\%) are sporadic (without a family history of CRC) acquiring somatic mutations and epigenetic alterations from modifiable risk factors (4). CRC due to hereditary components is estimated to be approximately $35-40 \%(5,6)$ while family history attributes to approximately $25 \%$ of cases without any disease phenotype (3). CRC is found to be inheritable in 5\% of cases known as hereditary non-polyposis CRC (HNPCC) or familial adenomatous polyposis (FAP) induced 
by adenomatous polyposis coli (APC), MutL homolog 1 (MLH1) and MutS homolog (MSH2) germline mutation (3). The development of CRC involves 3 global genetic and epigenetic aberrations: i) Chromosomal instability (CIN); ii) methylation of $\mathrm{CpG}$ island methylator phenotype (CIMP); and iii) instability of microsatellite DNA regions (MSI) (7-9). The majority of sporadic cases of CRC (85\%) result from CIN due to structural and numerical alterations, leading to the loss or gain of chromosomal segments, rearrangements leading to genetic instability and the loss of heterozygosity (10). The loss of heterozygosity $(\mathrm{LOH})$ causes alterations in copy number variations. On the other hand, CIMP augments alterations in the methylation frequency of $\mathrm{CpG}$ islands in promoter regions of tumor-suppressor genes, rendering their subdued expression or complete silencing $(11,12)$. Noticeable CRC cases have also been attributed to the unstable nature of microsatellite DNA (MSI) causing an alteration in the microsatellite length and are caused by the loss of DNA mismatch repair gene MLH1 driving hypermethylation and subsequent gene silencing (13). Alteration in these events results in the perturbation of tumor-associated genes, leading to changes in the cell cycle, which ultimately affects different cellular behaviors viz. cellular invasion, migration, proliferation and altered cell-to-cell signaling, leading to initiation and progression to CRC.

Naturally, the progression of CRC results from 4 steps: i) Initiation; ii) promotion; iii) progression and iv) metastasis (14). In initiation, irreversible genetic alteration leads to neoplastic transformation. Promotion involves cell proliferation leading to abnormal growth. In the progression phase, these genetic/epigenetic aberrations provide a selective advantage to cells, converting benign cells to malignant cells, which further progress to gain aggressive characteristics and metastasis, which is indicative of advanced disease characteristics with the potential to spread to other organs of the body through the blood and lymph nodes.

The detection of CRC is defined as stages that reflect the extent of disease progression. As per the American Joint Committee on Cancer, the staging of CRC is based on the TNM (tumor-nodes-metastasis) system (15). Tumor stage (T) characterizes the extent of tumor infiltration into the bowel wall, nodal stage $(\mathrm{N})$ refers to local or regional lymph node spread and metastatic spread (M) defines the presence of distant metastasis. After the TNM characterization, the disease is assigned into 4 stages (I-IV) categorizing stages I-II as early and stage III-IV as late-stage CRC (15).

Alterations in genetic and epigenetic components lead to the aberrant activation of signaling pathways, a pre-requisite for the progression from a benign to a malignant tumor. Crosstalk between signaling pathways further promotes the disease stage to metastasis, which is the main cause of CRC-related mortality (16). Despite advancements being made in early diagnosis and treatments that include surgery and chemotherapy, significant numbers of patients with early-stage CRC tend to develop metastasis and thus succumb to the disease. With the advent of robust next-generation sequencing techniques, numerous deleterious single nucleotide polymorphisms (SNPs) and mutations have been identified in genes directly or indirectly linked with CRC that may be the cause of carcinogenesis (17). According to Fearon and Vogelstein (18), a tumor acquires driver mutations, leading to the dysregulation of signaling pathways specifically targeting cell growth and differentiation, leading to colorectal carcinogenesis and further resulting in the metastatic phenotype. The most prevalent is the Wnt signaling pathway resulting from the APC mutation and is regarded as the earliest genetic lesions to induce cell transformation (19). Thus, understanding the signaling pathways underlying the adenoma-carcinoma sequence is essential for the identification of novel biomarkers for diagnosis and targeted therapeutics for CRC treatment. The present review article discusses various incidences and events linked with the development and progression of CRC and dysregulation in signaling pathways (Wnt, epidermal growth factor receptor (EGFR), PI3K/AKT, vascular endothelial growth factor (VEGF), hepatocyte growth factor (HGF)/mesenchymal-epithelial transition factor (cMET), Notch, Hedgehog, Hippo, NF-E2-related factor 2 (Nrf2) and immune checkpoint) that can cause malignancy. An overview of multiple targeted therapeutics that may help attenuate the course of the disease is also presented.

\section{Incidence of colorectal cancer}

The acquisition of genetic and epigenetic aberrations leads to the transformation of normal cells into benign lesions, which later become malignant. CRC arises as adenocarcinoma from glandular epithelial cells of the large intestine comprised of the colon and rectum. The development of CRC may take several years by establishing the dysregulation of several signaling pathways and avoiding multiple regulatory routes. Malignant cells arising in the large intestine constitute CRC. This includes the colon and rectum and since these include common features, it is grouped and termed 'colorectal cancer'. CRC is the most prevailing cancer of the gastrointestinal tract. The growth of the majority of CRCs begins in the innermost colon linings or rectum in the form of polyps. Not all polyps are cancerous; however, depending on their type, over time, some polyps can become cancerous. There are 2 main types of polyps: i) Adenomatous polyps, which are termed 'pre-cancerous' as they can sometimes develop into cancer; and ii) hyperplastic polyps (HPs) and inflammatory polyps, which are common, and they are generally not pre-cancerous. Several other factors can increase the risk of polyps developing into CRC, such as: If the polyp size increases by $>1 \mathrm{~cm}$, if the number increases by $>2$, and if dysplasia occurs following polyp removal.

As has long been considered, CRC develops using the classical pathway of adenoma to carcinoma route (20). Recently, another alternate pathway was coined as the serrated pathway. In this pathway, HPs were regarded as insignificant and only adenomas were responsible for CRC; accumulating evidence indicates that serrated polyps may form precursors to CRC, as well as through the serrated neoplasia pathway (21). Currently, patients with CRC with several serrated polyps classified as serrated polyposis syndrome have been demonstrated to have an increased risk of developing CRC (22). Small tumors are diagnosed within serrated lesions. It has been suggested that 10-30\% of CRC cases develop from the serrated neoplasia pathway (23).Longacre and Fenoglio-Preiser described serrated adenomas for the first time (24). Serrated polyps are heterogeneous lesions histologically marked by glandular serration. 


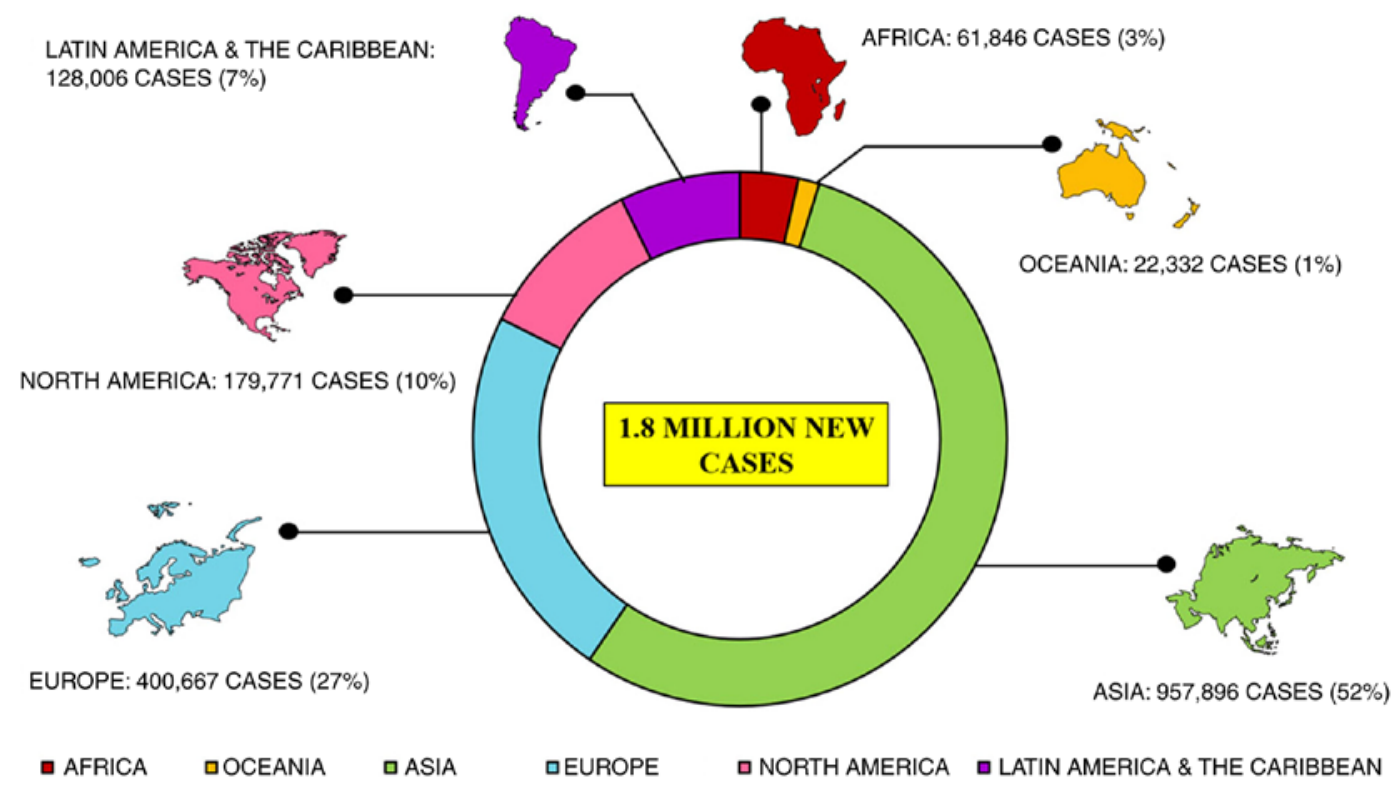

Figure 1. Map showing estimated age-standardized cancer incidence rates (worldwide) in 2018, colon and rectum, both sexes, all ages [reproduced from http://globocan.iarc.fr/ (31)].

Colonic epithelial cells from crypts display luminal saw-toothed morphology. In 2010, the WHO classified serrated polyps into 3 groups: i) HPs; ii) sessile serrated adenoma/polyps; and iii) traditional serrated adenoma (TSA) (25). Three-quarters of serrated polyps constitute HPs. HPs establish earlier than traditional adenomas; however, after 50 years, their occurrence does not increase significantly $(26,27)$. They develop as flat, sessile and pale lesions of approximately $5 \mathrm{~mm}$ in diameter and are etiologically located at the end of rectal mucosa folds. Sessile serrated adenoma/polyps (SSA/P) represent $15-20 \%$ of all serrated polyps and these lesions are either flat or slightly elevated located in the proximal colon $(28,29)$. TSAs are not very common polyps and constitute up to $5 \%$ of serrated polyps. They are found in the elderly and are located on the left side of the colon (30).

Incidence rates worldwide. $\mathrm{CRC}$ is the third most major type of cancer diagnosed in both sexes globally. Approximately 1.8 million new cases are reported annually that account for approximately $10 \%$ of all common cancers investigated globally, leading to approximately 9 million fatalities in 2018 itself that is $9.2 \%$ of all the cases investigated globally (31), as per the International Agency for Research on Cancer report 2018. Reports suggest a large topographical variation in the incidence and mortality of CRC among several countries worldwide (Fig. 1) (7). CRC is more prevalent in developed countries than economically transitioning countries (Brazil, Slovakia and China) where incidence rates have increased; however, the overall risk of CRC remains low. Incidence rates are decreasing with a higher human development index (HDI; North America and Europe), trailing a peak (USA, New Zealand and France), or increasing (Spain, Italy and Norway). In Saudi Arabia, CRC is the most common type of cancer in males (19.6\%), while the third most common cancer in females (9.5\%), causing highest cancer-related mortality (32). Several countries have taken major initiatives, such as screening, resulting in the early detection of CRC along with better treatment management that has decreased mortality rates. However, some countries still need to improve the screening process with a more effective medical set up, so that CRC can be detected at an early stage and thus treatment can be improved. Statistics suggest a spike in CRC growth and mortality rates after 50 years of age. An estimated $90 \%$ of worldwide cases and deaths have been observed after this age. It is also noteworthy that the incidence rate in males is $30 \%$ higher compared to females, with wider variations for rectal cancer $(60 \%$ higher) than for colon cancer (30\% higher). Females also exhibit a lower susceptibility to malignancy overall. Older females, however, ( $\geq 50$ years) are more prone to developing adenomas in the proximal colon than males. Sex inequalities and lifestyle habits follow differences in exposures to risk factors, such as smoking and sex hormones, as well as complex interactions between these factors.

\section{Types of colorectal cancer}

The majority of CRCs are adenocarcinomas, a type of tumor that contributes to $96 \%$ of colon and rectal cancers. These adenocarcinomas line the inside of the colon and rectal tissues. Despite its occurrence in the large intestine, CRC is a deeply heterogeneous disease with subtype variations, causes and clinical outcomes. Depending on its anatomical site, CRC subtypes have been divided into 3 segments: Proximal colon, distal colon and rectal cancer (Fig. 2A) (33). The proximal and distal colon located within the peritoneal cavity and the rectum lies within the pelvis. The embryo of the proximal colon usually begins from the midgut, whereas the distal colon contains segments from the splenic flexure to the upper anal canal and rectum appears from the hindgut. These subtypes are comprised of branches of the superior and inferior mesenteric artery, respectively. Several studies reveal that CRC subtypes present at different anatomical sites possess distinct risk factors i.e., smokers are at an increased risk of proximal colon cancer and rectal cancer (34). Due to etiological heterogeneity 


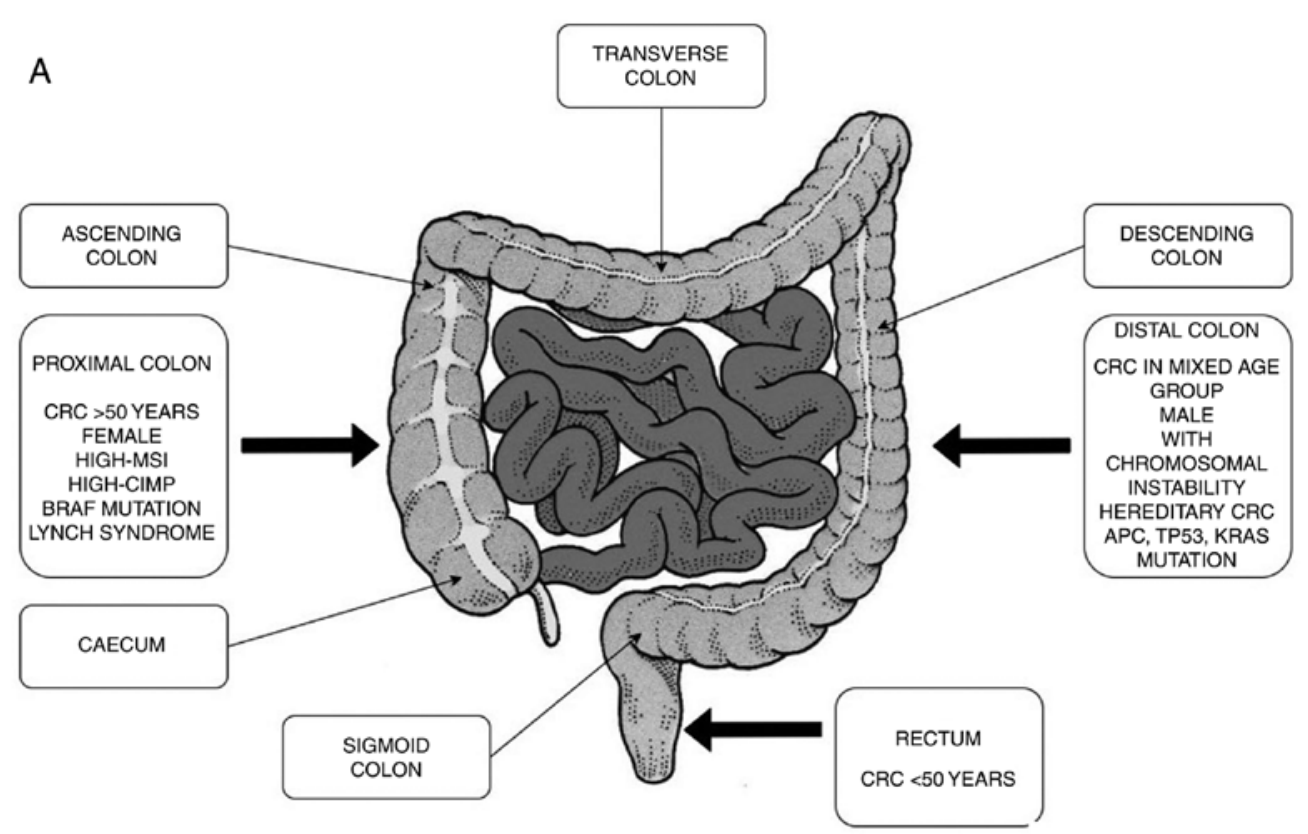

B

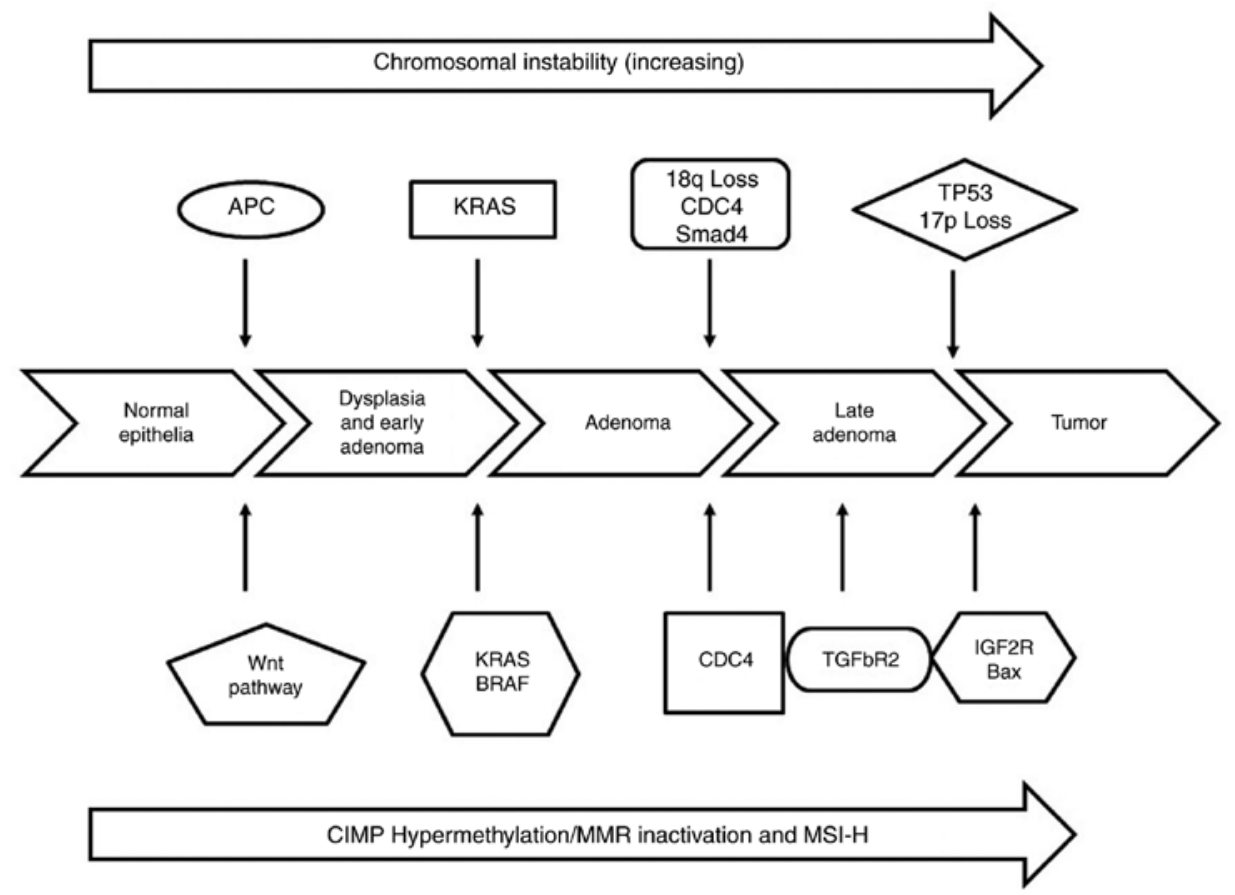

Figure 2. (A) Anatomical subtypes of colorectal cancer and their associations with tumor molecular features and other factors. (B) Colorectal adenoma-carcinoma sequence. The APC mutation is the first step transforming normal colorectal epithelium to adenoma. The adenoma-carcinoma sequence is caused by three major pathways: CIN, MSI and CIMP. CIN, chromosomal instability; MSI, microsatellite instability; CIMP, CpG island methylator phenotype; APC, adenomatous polyposis; KRAS, KRAS proto-oncogene GTPase; $B R A F, \mathrm{~B}$-Raf proto-oncogene serine/threonine kinase; TP53, tumor protein 53; LOH, loss of heterozygosity; HNPPC, hereditary non-polyposis colorectal cancer; $M L H 1$, mutL homolog 1; MSH2, mutS homolog 2; DCC, DCC netrin 1 receptor; TGFBR, transforming growth factor- $\beta$ receptor; $B A X, \mathrm{BCL} 2$ associated $\mathrm{X}$ apoptosis regulator; $I G F 2 R$, insulin like growth factor 2 receptor; $C D C 4$, cell division control protein 4.

of CRC with tumor locations, major functions, such as nutrient absorption and fecal storage of the colon and rectum occurs in distinctly different segments of the large intestine, for example, sodium and water absorption rates are highest in the cecum and decrease progressively towards the rectum. This is also due to the functional variations of different segments of the large intestine. Demographic factors also contribute to the risk associated with CRC. The European Prospective Investigation into Cancer cohorts places females at a higher risk of proximal colon cancer (34\%) compared to males (25\%) (34) and this is age-dependent i.e., increases with age (35\% for individuals $<60$ years of age to $60 \%$ for individuals $>70$ years of age) (35). It has also been observed that subtypes of CRC are widely distributed based on ethnicity: Proximal colon cancer is more prevalent among Caucasians and individuals of African origin (USA: Proximal colon cancer accounts for 44 and $49 \%$; rectal for 29 and 25\%; and distal for 27 and $26 \%$ among Caucasians and African-American individuals, respectively) (36). In Asian countries, such as Korea, rectal cancer is more prevalent (rectal, 52\%; proximal, 22\%; and distal, 26\%) (37), whereas, 
32-34\% of each subtype CRC cases are uniformly shared among Asian-Pacific Islanders (API) across the 3 colorectal sections (36).

Hereditary and non-hereditary CRC. The majority of CRC cases are sporadic with no family history or a predisposition to illness in individuals, although almost 1 out of 3 individuals with a family history of CRC develop the disease. The average lifetime risk of developing $\mathrm{CRC}$ in most western populations is in the range of 3-5\%. However, individuals with a family history of CRC in first-degree family members diagnosed at 50-70 years of age are at a double risk; the risk triples if the relative is $<50$ years of age at the time of diagnosis. The risk of developing CRC increases with $\geq 2$ diagnosed first-degree family members at any stage. There may be several reasons for the increased risk, such as genetics, environmental factors, or a combination of both. Approximately 5-10\% of the specific subgroup of individuals who develop CRC symptoms have inherited gene mutations that cause hereditary cancer syndrome, rendering them prone to developing the disease. It has been observed that FAP and HNPCC also known as Lynch syndrome, are the most prevailing inherited syndromes linked to CRC, accounting for approximately 2-4\% of all CRC cases (38).

HNPCC/Lynch syndrome. HNPCC is the most widespread inherited colorectal syndrome with an estimated 1 in 3,000 affected individuals in western populations (39). Germline mutations in any of the mismatch repair genes, namely MLH1, MSH2, MSH6, PMS2 and epithelial cell adhesion molecule (EPCAM) have been reported to be associated with HNPCC. Generally, tumors harbor MSI (40), which primarily occurs due to the inability to rectify strand slippage within repetitive DNA sequences, leading to alterations in the mononucleotide or dinucleotide repeats, thus also altering the size and arrangement of microsatellites, which are strewn throughout the genome (12). This can be identified by a PCR test and immunohistochemical analysis, which can pinpoint the loss of expression of the mismatch repair protein factors (40-43). Individuals affected with 'non-polyposis' tend to have polyps from the defined spectrum, leading to cancer progression within 2-3 years, as compared to the 8-10 years of the 'normal' community.

FAP. FAP is the second major type of hereditary CRC syndrome, which accounts for $>1 \%$ of all CRC cases (44). This syndrome affects almost 1 in 11,300-37,600 individuals in the European Union (45) and is caused by hereditary germline mutation in the APC gene, which regulates the activity of the Wnt signaling pathway (46). Unlike patients with HNPCC who develop a few adenomas, patients with FAP tend to develop numerous adenomas, primarily in the distal colon at a younger age (44). Among the numerous adenomas in FAP, one or more adenomas undergo malignant transformation, virtually increasing the risk of developing CRC to $100 \%$ by 40 years of age, unless the colon, or sometimes the rectum, is not removed (47).

Early-onset colorectal cancer (EOCRC). The incidence of EOCRC is increasing in countries, such as the USA and Canada at an alarming rate, becoming the second most common type of cancer, and the third most common cause of cancer-related mortality in individuals $<50$ years of age (48). Over the past 4 decades, the incidence of EOCRC has increased rapidly and by the year 2030, it is further expected to increase by $>140 \%(49,50)$. The incidence rates are inversely associated with age i.e., increasing significantly in younger individuals and decreasing in older individuals. Up to $13 \%$ of cases of EOCRC have been reported to be linked to a germline mutation in mismatch repair genes mentioned above, underlying hereditary CRC syndromes (51). Although early-onset CRC patients have a higher risk of the prevalence of hereditary syndrome, approximately half the patients with early-onset CRC do not have any family history of the disease (52). Studies have indicated a prominent difference in pathological characteristics between the elderly and younger groups of CRC patients (53), demonstrating an increase in EOCRC at a younger age, but often being detected at a higher stage $(54,55)$. CRC diagnosed in younger patients is commonly symptomatic, at a later stage, mucinous and involves poorly differentiated tumors (56-58). The cancer-specific survival of younger individuals is markedly higher than older individuals (53). No statistically significant difference in the disease-free survival between these 2 groups has been demonstrated over the past 5 years $(63.2 \%$ in both the young and elderly group) (53). Between 1992 and 2014, there was a significant increase in the number of young male patients with CRC than older patients (53.3\% in the young and $49.7 \%$ in the older group). Compared to patients of a screening age $(\geq 50)$, younger patients with CRC were mostly of African origin (16.8 vs. 10.4\%), Asian/Pacific Islander (API) (5.6 vs. $2.2 \%$ ) and Hispanic (13.1 vs. 6.0\%). In younger patients with CRC, there are high proportions of rectal (39.5 vs. 27.7\%) and distal colon (43.9 vs. $33.8 \%$ ) cancers as compared to elderly patients with a higher percentage of proximal colon cancers (58.2 vs. $48.2 \%$ ) (54). However, the reason for EOCRC remains unclear, although certain risk factors, such as prolonged exposure to carcinogens and early childhood exposure serve as critical determinants of risk (31).

Several other physical factors, such as body weight, age, sex, body mass index (BMI) and lifestyle behaviors, such as smoking, etc. have also been associated with EOCRC. Weight loss may be an early symptom of EOCRC (59). Furthermore, females with a BMI of $>30$ have a higher risk of developing EOCRC $(95 \%$ CI, 1.15, 3.25) compared to those with a normal BMI (60). Low et al suggested that smoking is not associated with the risk of EOCRC; neither current nor former smokers are at a risk of developing CRC as compared to non-smokers (59). Rectal cancer has a higher chance of developing into EOCRC than colon cancer, whereas, in late-onset cases, obesity is the major risk factor for colon cancer $(61,62)$. These differences indicate several factors associated with EOCRC and further studies are required to identify the major associated risk factors.

\section{Mutation basis and occurrence of colorectal cancer}

$\mathrm{CRC}$ is a heterogeneous disease, resulting from the continuous accumulation of both genetic and epigenetic alterations within cells, leading to the transformation from a colorectal adenoma to a colorectal adenocarcinoma. This transformation 
is associated with 3 major pathways of genome instability, namely CIN, MSI and CIMP, of which the latter 2 fall under the alternate serrated pathway (Fig. 2B) (63). The most common is CIN (chromosomal number and structural alterations) that leads to karyotyping variability among cells (64). The second most common pathway is MSI (molecular alteration and hyper-mutable phenotype), which constitutes approximately $15-20 \%$ of CRC (65) caused by defective DNA mismatch repair system (66). MSI can be defined as 'alterations in the number of repetitive DNA in microsatellites (also known as short tandem repeats) throughout the genome sequence (67). The third pathway contains a high density of methylated genes termed CIMP cancers (68). This type of cancer is mainly located on the proximal side of the colon (up to $40 \%$ of the cases) and appears in serrated polyps instead of adenomas (69).

\section{Molecular pathways of colorectal cancer}

CIN pathway. A number of studies have concluded that the majority of human tumors are heterogeneous in nature forming a 'mutator-phenotype' due to continuous accumulation of multiple mutations that occur during cell division in cancer cells that generally function to maintain genetic stability (70). Both CIN and MSI are well defined and detected by karyotype and PCR-based analysis, respectively; however, due to difficulty in predicting random mutations, particularly point mutations that limit the search for evidence of a mutator phenotype at single base-levels (70), the 'mutator phenotype' may exhibit various manifestations, including increased mutation rates and genetic evolution of cancer cells that propel tumor progression (71). The mutator-phenotype may be an attractive target for cancer therapy due to common features in the majority of cancers (72).

CIN appears in $70 \%$ of sporadic CRC cases. CIN causes an alteration in chromosome number, involving gain or losses of the whole or a large part of chromosomal aneuploidies, resulting in a rearrangement of chromosomes (karyotyping) from cell to cell (73). LOH and an imbalance in chromosome number (aneuploidy) are the most common characteristics of CIN. There are several techniques to measure CIN, such as cytometry, LOH analysis, karyotyping, fluorescent in situ hybridization (FISH) and a recently developed technique known as comparative genomic hybridization (CGH). CGH utilizes DNA microarray or 'chips' that are commonly used to detect copy number variations (74). In this advanced CGH microarray technique, cloned DNA fragments with precise genomic positions are used against the metaphase chromosomal arrangement in conventional CGH (75). It is not always upfront to categorize tumors as CIN-positive vs. CIN-negative based on these different methods and criteria rather different sub-categories of CIN-high and CIN-low for CIN-positive tumors have been proposed in several studies (76-78). Moreover, CIN contributing to CRC tumorigenesis through the aggregation of mutations in specific oncogenes, including B-Raf proto-oncogene serine/threonine kinase (BRAF), KRAS proto-oncogene GTPase (KRAS), tumor protein p53 (TP53) and tumor-suppressor APC gene (12,75). The multistep genetic model proposal by Fearon and Vogelstein, which is now widely accepted, examines the different stages of tumor development i.e., from small adenomas to large adenocarcinomas (18). The model demonstrates the various events occurring at different stages of tumor development i.e., from normal colorectal epithelium to metastatic carcinomas (79). The first event is the mutation of APC, transforming normal colorectal epithelium to adenoma, followed by oncogenic KRAS mutation at early adenomatous stage and ultimately inactivation of the tumor-suppressor gene TP53 on chromosome 17p and the deletion of chromosome $18 \mathrm{q}$ occurring during the progression to malignancy (80-82). APC is a tumor suppressor gene located at chromosome 5, which is responsible for familial adenomatous polyposis constituting approximately $85 \%$ of colorectal cancer cases without a hereditary relationship $(83,84)$. APC and CTNNB1 ( $\beta$-catenin) are the most frequently mutated genes in CRC. APC mutation breaks the association between APC and $\beta$-catenin, resulting in a large amount of $\beta$-catenin in the cytoplasm and the overactivation of the Wnt signaling pathway. Followed by tumor-formation promoting gene translocation to the nucleus and interacting with other transcription factors involved in tumorigenesis and invasion (85). K-RAS is located on chromosome 12 and is one of the most bulging proto-oncogenes in colon carcinogenesis. RAS family proteins are involved in signal transduction. K-RAS activates the mitogen-activated protein kinase (MAPK) pathway eliciting the nuclear expression of early response genes. RAF proteins are activated by the GTPase activity of RAS (86). Thus, K-RAS mutations result in colon cancer formation in the early adenomatous stage and contribute to its formation by $37-41 \%(87,88)$. The allelic loss in chromosome $18 \mathrm{q}$ is observed in $70 \%$ of primary CRC cases in the late-stage adenomas (89) and exhibits a strong association with a poor prognosis (90). The inactivation of tumor-suppressor genes, including deleted in colon cancer (DCC), SMAD2 and SMAD4 present on the $\mathrm{q}$ arm of chromosome 18 due to $\mathrm{LOH}$ plays a significant role in CRC $(18,82,91)$. The SMAD proteins are involved in TGF- $\beta$ signaling and in the regulation of genes involved in cell cycle programming (92). Since SMAD2 and SMAD4 are located on chromosome $18 \mathrm{q}$, the loss of chromosome $18 \mathrm{q}$ leads to the deregulation of the TGF- $\beta$ signaling pathway and contributes to colorectal carcinogenesis $(93,94)$. DCC is localized in the chromosome band 18q21.2 and is deleted in approximately $70 \%$ of the cases (95). However, no evidence supports the role of DCC in colorectal tumorigenesis (96). Patients with $18 \mathrm{q}$ LOH $(70 \%)$ have an increased 5-year survival rate in stage II than those without $18 \mathrm{q}$ LOH (43\%), which leads to the analysis of the impact of adjuvant therapy in stage II (97). There is an increase in the 5-year survival rate of patients with $18 \mathrm{q} \mathrm{LOH}$ receiving adjuvant therapy compared to those without $18 \mathrm{q}$ LOH (90 vs. 37\%; P=0.01) (97). The TP53 gene located on the short arm of chromosome 17p13.1 consists of 11 exons and 10 introns and is commonly lost in colorectal carcinoma $(20,98)$. The TP53 mutation is most common in human cancers with $43.28 \%$ in CRC resulting in the loss of tumor suppressor activity or (gain of function) to support tumor progression (99). The majority of mutations occur in exon 5 to 8 (DNA binding domain) $(100,101)$. To date, the majority of TP53 mutations detected in CRC are missense mutations with AT for GC substitution (102). p53 is known as the 'guard of the genome' due to its ability to respond to mutagenic stress, such as DNA-damage and repair, cell cycle arrest and apoptosis (103). It also inhibits the development of new blood 
Table I. List of modifiable and non-modifiable risk factors for colorectal cancer.

Modifiable risk factors

Increases the risk of colorectal cancer

Lowers the risk of colorectal cancer

\section{Smoking}

Processed meat

Alcohol intake

Red meat

Low intake of vegetables and fruits

Body fat and obesity

Non-modifiable risk factors

\author{
Physical activity \\ Whole grains \\ Dietary fiber, tree nuts \\ Dairy products \\ Fish intake \\ Vitamins (D, C and others), calcium supplements
}

Hereditary factors

Hereditary colorectal cancer syndromes

Positive family history
Other factors

Aspirin or NSAID use

Menopausal hormone therapy

Statin use

Ethnicity, male gender

Type 2 diabetes and Inflammatory bowel disease vessels (angiogenesis) through the induction of TSP1 (104). However, a mutation in p53 leads to oligomerization of the wild-type and mutant p53, which can block the function of TP53, resulting in the loss of DNA binding specificity (105).

MSI. The second most common genomic instability is the hyper-mutable phenotype (MSI) (106). MSI generally occurs due to damaged mismatch repair (MMR) along with the slippage of DNA polymerase which creates a short-term insertion-deletion loop (IDL) (106). These defects result in the alteration of the size of the allele as compared to those detected in the normal cells of the same individual. The DNA MMR system has several proteins (such as MLH1, MSH2, MSH6 and PMS2) that repair single base pair mismatch, incorporated into micro-satellites during DNA synthesis to maintain genomic stability. MSI CRC mostly occurs in the proximal colon (107). Several studies have examined MSI a prognostic biomarker for CRC. The Bethesda guidelines proposed the first panel of MSI markers consisting of 5 microsatellite markers viz. mononucleotides (BAT25 and BAT26), and dinucleotides (D2S123, D5S346, and D17S250) to access the status of CRC (108). CRC can be classified based on the percentage of loci with MSI. In particular, $>30 \%$ of unstable markers are classified as CRC with MSI-high (MSI-H), those with $<30 \%$ markers exhibiting instability are termed MSI-low (MSI-L), and markers with no instability are termed microsatellite stable (MSS) (109). Defects in MMR genes occur either by mutational inactivation or by epigenetic silencing of $\mathrm{CpG}$ island hyper-methylation of the MLH1 gene promoter (9).

The results of immunohistochemistry of CRC reveal the interaction between MMR proteins PMS2 and MSH6 with other repair factors, such as MLH1 and MSH2, respectively. Therefore, the inactivation of MSH2 is frequently associated with the loss of the expression of MSH6, which is highly acceptable in MSH2 germline mutation. Similarly,
MLH1 inactivation is frequently associated with the loss of expression of PMS2, which may result either from MLH1 germline mutation or by the epigenetic silencing of $\mathrm{CpG}$ island hyper-methylation of the MLH1 gene promoter. Germ-line mutations of MSH6 and PMS2 are generally associated with the individual loss of expression of MSH6 and PMS2 proteins, respectively (110).

CIMP. CIMP represents a subset of CRC that contains a high density of hyper-methylated genes, causing transcriptional silencing within the promoter region, resulting in the loss of gene expression (111). CIMP contributes to approximately $30-35 \%$ cases of colorectal adenomas, occurring at an early stage and as a precursor to the serrated pathway of colorectal tumorigenesis (112-114). CpG island hypermethylation present in the tumor suppressor gene promoter region results in gene silencing. The hypermethylation of MLH1 leads to its silencing and dysregulates MMR (mismatch repair) function (114). CIMP constitutes a prominent molecular characteristic of the serrated neoplasia in $20-30 \%$ of CRC cases $(115,116)$. CIMP has also been found histologically in patients with hyperplastic polyposis syndrome, suggesting that it is an important early event of the serrated neoplasia pathway (117). The inactivation of MLH1 by hypermethylation leads to the induction of MSI-H followed by additional mutations in MSH3, MSH6, Bax, insulin-like growth factor 2 receptor (IGF2R) and phosphatase and tensin homolog (PTEN), resulting in the development of dysplasia and cellular transformation $(118,119)$. Studies suggest that the serrated pathway is responsible for the rapid development of $\mathrm{CRC}$, as compared to patients with CRC with Lynch syndrome $(120,121)$.

\section{Risk factors}

Risk factors increase the chance of acquiring a disease. Several factors, such as environment and lifestyle have been associated 
with the increased occurrence of CRC (Table I). Smoking, an increased BMI, intake of red meat, lack of regular physical activity and poor diets are associated with an increased risk of CRC (122). Various studies show that approximately $12 \%$ of CRC-related deaths are due to cigarette smoking. Tobacco smoke contains at least 70 chemicals classified as carcinogens. Smoking is associated with the early onset and distal location of CRC in males (123). The relative risk of CRC due to prolonged heavy smoking is 1.18 (95\% CI, 1.11-1.25) (124). A previous study found larger polyps in the colon and rectum of long-time heavy smokers (123). Additionally, patients with Lynch syndrome (also known as HNPCC), who also smoke regularly, are at a higher risk of developing CRC as compared to former smokers, short-term smokers and light smokers (125). Smoking is strongly associated with serrated polyps (relative risk (RR), 2.33 (95\% CI, 1.76-3.07), particularly in the left side of the colorectum and a weak association with adenomas (RR 1.31 (1.08-1.58) (126). Evidence points to the role of epigenetic modification in smoking-related CRC. Smokers with MSI-H tumors (RR, 1.99; 95\% CI, 1.26-3.14), CIMP-positive tumors (RR, 1.88; 95\% CI, 1.22-2.90) and BRAF mutation-positive tumors (RR, 1.92; 95\% CI, 1.22-3.02) are at a higher risk of developing CRC (127). In a cohort study from the USA, former smokers that had quit smoking prior to 40 years of age or had quit for $\geq 30$ years, were at no risk of developing CRC (128). A previous meta-analysis revealed a significant association of smoking cessation with improved an overall survival ( $\mathrm{HR}<10$ years, 0.78 ; 95\% CI, $0.69-0.88 ; \mathrm{HR} \geq 10$ years, 0.78 ; 95\% CI, 0.63-0.97) and CRC-specific survival (HR $\geq 10$ years, 0.76 ; $95 \% \mathrm{CI}, 0.67-0.85)$ as compared to smokers who had not quit (129).

Several studies have associated alcohol consumption with an increased risk of developing CRC. Alcoholic beverages contain reactive metabolites known as acetaldehydes, which can be carcinogenic and mutagenic and are responsible for alcohol-dependent carcinogenesis (130). A meta-analysis of 27 cohorts and 34 case-control studies observed that there was a significant increase in the risk of developing CRC for moderate (2-3 drinks per day; RR, 1.21; 95\% CI, 1.13-1.28) and heavy drinkers ( $\geq 4$ drinks per day; RR, 1.52; 95\% CI, 1.27-1.81), as compared to non-drinkers (131). Nevertheless, another meta-analysis published in 2018 on 14 cohorts in North America, Europe and Asia revealed a significant increase in the risk of CRC for light drinkers $(\leq 1$ alcoholic drinks per day) as compared with non-drinkers/occasional drinkers (132). The increased risk of CRC is generally higher in males than in females, possibly due to the higher alcohol consumption (133). In 2012, the worldwide incidence and mortality rates of all cancer cases due to alcohol consumption were 5.5 and $5.8 \%$, respectively (134). A total of $3.5 \%$ of all cancer-related deaths in the USA are due to alcohol consumption (135).

Alcohol dehydrogenase is a key metabolic enzyme that metabolizes ethanol to acetaldehyde, which is then converted into acetic acid via aldehyde dehydrogenase (ALDH). The polymorphism ALDH2 $* 2$ in ALDH2 leads to an increased circulation of acetaldehyde, that can reach colonocytes. As compared to other parts of the world, the ALDH2 variant is very frequent among populations in East Asian. According to pooled studies in Japan, the relative risk associated with
$>45 \mathrm{~g}$ /day consumption of alcohol was 2.09 (95\% CI, 1.65, 2.64), but 1.41 (95\% CI, 1.16-1.72) in Europe and North America (133). A meta-analysis found that obnoxious symptoms of ALDH2 carrier that may be preventing them from consuming alcohol, thereby, reducing the risk of CRC by approximately $20 \%$.

Diet is strongly associated with the risk of developing CRC, with studies showing a $70 \%$ risk reduction by a change to a healthier diet and acquiring healthy food habits (135). Patients who consume a high-fat diet, particularly red meat, have been shown to have a higher risk of developing advanced CRC $(136,137)$. Colon cancer exhibits a stronger association with the consumption of meat than rectal cancer (138). The mechanistic link with the positive association of the consumption of red meat with CRC is the presence of heme iron in the former $(138,139)$. Meat cooked at a high temperature produces heterocyclic amines and polycyclic aromatic hydrocarbons, which are considered to possess carcinogenic properties $(138,140)$. Individuals consuming a diet rich in calcium (dietary and supplements), fruits, fiber and vegetables are at a decreased risk of developing CRC $(141,142)$.

Overweight and obese individuals are at a higher risk of fatality, with this being the fifth leading cause of cancer-related mortality. Approximately 2.8 million adults die of obesity-related cancer each year (143). In Europe, approximately $11 \%$ of CRC cases are associated with obesity and being overweight (143). Researchers have found a positive association between excess weight and cancer in both sexes; however, males were found to have a higher risk. This was attributed to lower testosterone levels in older males as compared to post-menopausal women with higher estrogen levels (144). Various studies found a significant positive association between CRC and BMI $(145,146)$; the overall RR for CRC predicted per $1 \mathrm{~kg} / \mathrm{m}^{2}$ of higher BMI was 1.03 (95\% CI, 1.02-1.03) (147). BMI expresses overall body fat and waist circumference (WC), representing abdominal fat; studies have reported that WC, more than only the BMI, is strongly connected to an increased risk of CRC $(148,149)$. Abdominal fat is divided into 2 categories: Visceral adipose tissue (VAT) and subcutaneous adipose tissue (SAT). VAT secretes higher levels of pro-inflammatory adipokines (such as TNF) and lower levels of adiponectin (an insulin-sensitizing hormone) as compared to SAT (150). Visceral obesity is more common among Asian populations than Caucasian populations for any given BMI (151). Evidence suggests a stronger association with obesity in males than in females, colon cancer over rectal cancer and distal cancer over proximal colon cancer (152). A previous meta-analysis reported a link between abdominal obesity and an increased risk of colorectal adenomas (RR, 1.42; 95\% CI, 1.30-1.56) (153). Another meta-analysis predicted a higher risk of developing CRC among diabetic patients $(21 \%$; 95\% CI, 1.02-1.42) as compared to non-diabetic individuals (154). Obesity can also cause hyperinsulinemia and insulin resistance (155) due to the lower expression of insulin-receptor levels and decreased intracellular insulin signaling in response to insulin receptor binding (156). This results in an escalated release of insulin, and lower insulin sensitivity, leading to an increase in free insulin-like growth factor 1 (IGF1). IGF is involved in the maintenance of tissue homeostasis, differentiated phenotype, growth regulation, proliferation, apoptotic 


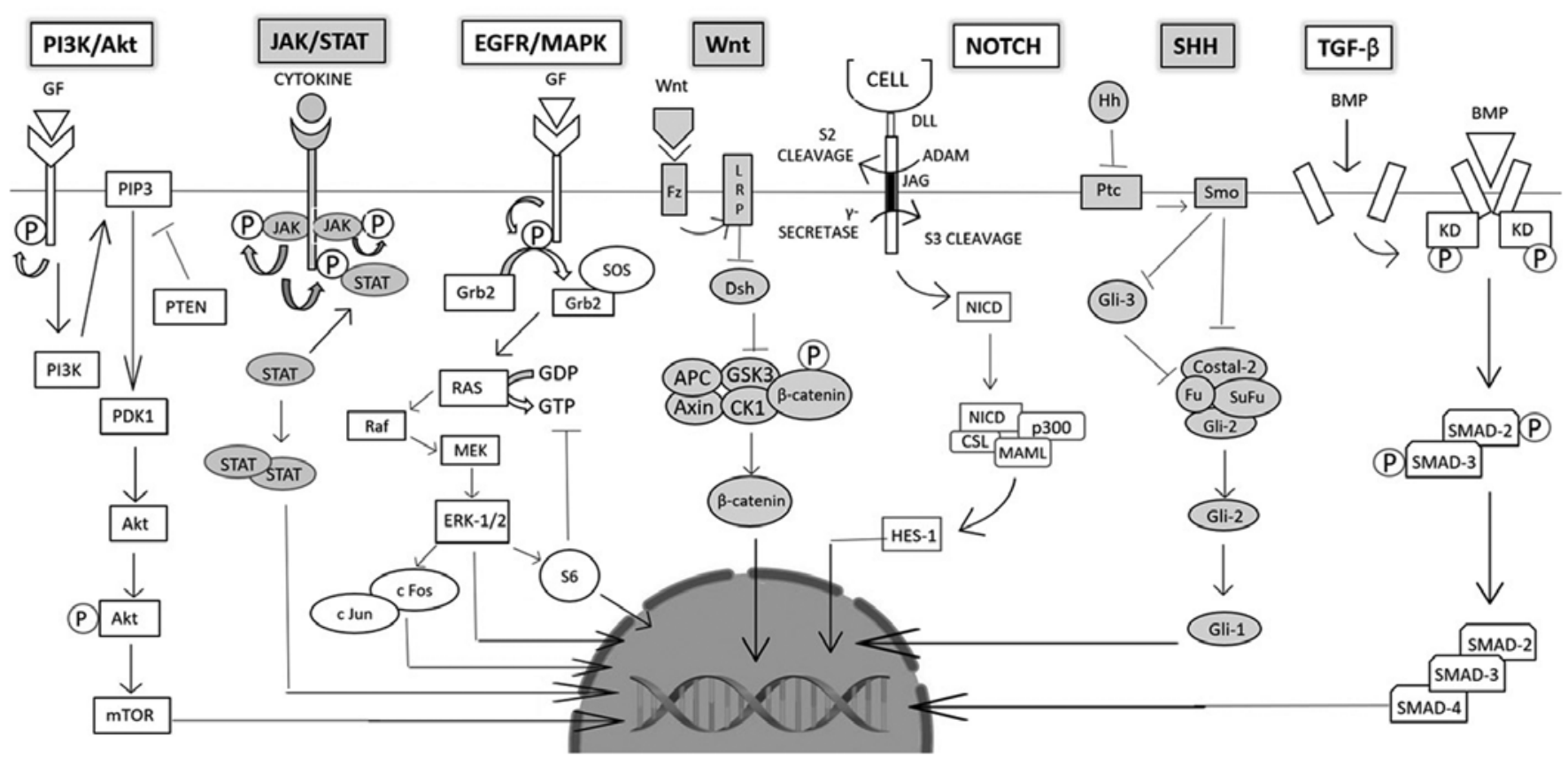

Figure 3. These pathways play an important role in cell growth, proliferation, and homeostasis, thus, a mutation in anyone may cause cancer cell survival, division and metastasis. These pathways include (from left to right) the PI3K/Akt pathway mutation linked with over-expression of Akt, causing cell division and the inhibition of apoptosis is reported in 70\% of CRC cases. The JAK/STAT pathway is associated with pro-inflammatory gene expression due to binding and activation of GAS elements; EGFR/MAPK pathway regulates the CREB transcription factor, and over-expression of EGFR is reported in CRC cases; Wnt pathway regulates the $\beta$-catenin levels in the cell and activate target genes such as MYC, CCND1 and AXIN2. The Notch pathway and associated Notch-1 have been found to be upregulated in CRC and adenocarcinomas; SHH pathway mutations are reported in CRC (Smo, Gli1 and Ptc); the TGF- $\beta$ pathway is 'lost' in cancer cells, thereby resisting growth inhibition; however, later stages of CRC report the pathway leading to EMT.

imbalance, angiogenesis, migration, cell adhesion and wound healing (157). The insulin/IGF1 signaling pathway promotes colorectal carcinogenesis by decreasing apoptosis and increasing cell proliferation (158). After menopause, adiposity becomes the main spot for estrogen production in women, protecting them against susceptibility to CRC $(159,160)$. Thus, cancer caused due to insulin and IGF1 in overweight/obese elderly women could be counteracted by the anticancer effects of estrogen (7).

An increased intake of dietary insoluble-fiber lowers the risk of colorectal epithelium carcinogenesis in the lumen by increasing fecal bulk, diluting fecal content, and decreasing transient time (47). Research has demonstrated a lower risk of developing CRC among rural Africans compared to Western populations, due to a higher fiber intake by the former (161). A nested case-control design predicted the association between the incidence of CRC and dietary fiber intake, concluding that cereal fiber and whole grains having a high dietary fiber content were inversely associated with the risk of CRC (RR for $10 \mathrm{~g}$ per day increment, $0.90 ; 95 \%$ CI, 0.83-0.97) as compared to fiber from fruits, vegetables and legumes (162). In their report, the World Cancer Research Fund (WCRF) and the American Institute for Cancer Research (AICR) added whole grains as a possible protective agent against CRC (163).

$\mathrm{CRC}$ is one of the few types of cancers that strongly suggests the absence of physical activity as a risk factor (164). It has been demonstrated that physical activity is inversely related and sedentary lifestyles are positively associated with the risk of CRC (165). A cohort study reported the benefits of aerobic exercise against digestive system cancers (of which CRC contributed to 56\%) with optimal levels detected at approximately 30 metabolic equivalent of task (MET) hours/week (HR, 0.68; 95\% CI, 0.56-0.83) (166). Regardless of the level of physical activity, sedentary activities, such as prolonged periods of sitting are strongly associated with an increased risk of CRC. For an increase of $2 \mathrm{~h}$ per day of television watching, the RR was 0.07 (95\% CI, 1.05-1.10; P<0.001) (167). Sedentary behavior results in weight gain in CRC survivors (168). In 2008, a prospective cohort study concluded that physical exercise or sports activity $>5$ times per week was associated with a lower risk of developing colon cancer among males $(\mathrm{P}=0.001$; RR, 0.79; 95\% CI, 0.68-0.91) and females ( $\mathrm{P}=0.376$; RR, 0.85; $95 \%$ CI, 0.70-1.04) as compared to very limited or no activity at all (169).

\section{Overview of dysregulated signaling pathways}

Intestinal epithelial cells renew constantly and are tightly regulated by several pathways (Fig. 3). Mutations in these pathways can lead to unchecked growth/delayed or failed apoptosis of epithelial cells, encouraging tumor formation, survival, angiogenesis and metastasis. The understanding of these pathways as targets of gene therapy to combat CRC is underway. While the dysfunction of a few growth and differentiation pathways may result in $\mathrm{CRC}$, understanding these mechanisms may help in the prevention of tumor formation.

Wnt/ $\beta$-catenin signaling pathway. The $\mathrm{Wnt} / \beta$-catenin pathway is highly conserved as it is essential to embryogenesis. Wnt proteins are growth stimulatory factors (the 
attached palmitoleic acid assisting in protein-binding). These proteins exhibit an abnormal cellular expression in patients with CRC. There are $19 \mathrm{Wnt}$ genes present in mammals and all play regulatory roles in several biological and developmental processes, such as cell fate determination, cell cycle, proliferation and migration. Membrane surface cell receptors comprise frizzled (Fz) and low-density lipoprotein (LDL) receptor-related protein (LRP) complexes at the cell surface. Along with this, there exists an intracellular complex comprising of several proteins, such as $\beta$-catenin, dishevelled (Dsh), axin, glycogen synthase kinase-3 $\beta$ (GSK-3) and APC. The protein complex regulates the level of $\beta$-catenin in the cell by proteasomal degradation. Following phosphorylation and ubiquitination (by $\beta$-trcp) of $\beta$-catenin, the transcriptional regulator is degraded by the cellular proteasome. Upon ligand-binding, the degradation process is inhibited, leading to the accumulation of active phosphorylated $\beta$-catenin in the cell. The $\beta$-catenin then translocates into the nucleus and induces transcription. Mutations in the APC gene can lead to colon cancer (reported in $90 \%$ of cases). The overexpression of Wnt is associated with tumorigenic activity and encourages tumor growth. Mutations in the $\mathrm{Wnt} / \beta$-catenin pathway lead to CRC development (170). This pathway also plays an essential role in tissue regeneration of hair, skin, intestine, etc. (171). The dysregulation of the Wnt pathway has been reported in a number of tumors, including CRC. The hyperactivation of this pathway is imperative for oncogenesis, leading to CRC development. Targeting Wnt/ $\beta$-catenin can be effectively used for the development of small molecules (172-175).

EGFR/MAPK signaling pathway. A catalytic receptor tyrosine kinase (RTK), EGFR, is present on the cell surface, having an extracellular ligand-binding domain. EGF acts as a ligand and binds to EGFR, resulting in the autophosphorylation of the tyrosine residues on the intercellular side of the transmembrane protein. This offsets a chain of cellular events; an adaptor molecule Grb-2 interacts with the phosphorylated tyrosine through its $\mathrm{SH} 2$ domain, followed by interaction with the son of seven-less protein (SOS) through the SH3 domain of Grb-2.SOS, a guanine nucleotide exchange factor, enables the conversion of GTP from GDP on the RAS molecule, thereby activating it. Activation initiation results in a kinase cascade, activating mitogen-activated protein kinase kinase kinase-Raf (MAPKKK), mitogen-activated protein kinase kinase-MEK (MAPKK) and MAPK or extracellular signal-regulated kinase (ERK) in turn through phosphorylation. ERK regulates cellular events, such as the proliferation and survival of cells by targeting cytoplasmic or nuclear substrates. Cytoplasmic substrates include c-fos and c-Jun (dimerized by MAPK) which enter the nucleus and interact with the AP-1 motif of the DNA, initiating transcription. ERK also phosphorylates cytoplasmic substrate, ribosomal S6 kinase (RSK). The S6 protein can perform one of two functions including, negative regulation of the SOS molecule (effectively turning 'off' the signaling pathway by inhibiting the conversion of GTP from GDP) or entering the nucleus and regulating the CREB transcription factor. MAPK may also directly regulate the nuclear substrate MYC. Inactivation of the pathway can also occur through the hydrolysis of GTP through the GAP protein.
The MAPK pathway engages in various cellular processes such as growth, proliferation and survival of cells. The deregulation of the pathway results in the stimulation of growth, survival, angiogenesis and metastasis of neoplastic cells. The mutation of the K-Ras gene has been reported in early cancer stages in almost $40 \%$ of CRC cases. Abnormal regulation, amplification, increased copy number and the overexpression of EGFR promoting MAPK activation has been reported in cases of CRC and is being studied as a possible and promising target for treatment (173-175).

PI3K/AKT signaling pathway. The PI3K pathway is associated with cell growth, proliferation and differentiation. The enzymatic receptor tyrosine kinase upon ligand-binding, autophosphorylates and activates phosphatidylinositol 3-kinase (PI3K) that has two subunits: p85 and p110. PI3K then, in turn, phosphorylates lipid protein, phosphatidylinositol-4, 5-biphosphate (PIP2) to phosphatidylinositol-3,4,5-triphosphate (PIP3). PIP3 signals proteins, such as 3-phosphoinositide-dependent protein kinase 1 (PDK1) that activates protein kinase $\mathrm{B}$ (AKT/PKB) by acting upon its serine and threonine residues. AKT may be of 3 subtypes (AKT-1, AKT-2 and AKT-3) depending upon whether it has been encoded by $\operatorname{PKB} \alpha, \operatorname{PKB} \beta$, or $\mathrm{PKB} \gamma$, respectively. AKT targets downstream proteins, such as mammalian target of rapamycin (mTOR), which is responsible for cell cycle progression, proliferation, delayed apoptosis, growth and survival. Phosphatase and tensin homolog protein (PTEN) downregulate the pathway by dephosphorylating PIP3. PTEN is also a tumor-suppressing molecule. The aberrant expression of the pathway (inability to switch-off) results in continuous and unchecked growth and survival of cells leading to cancer. PI3K consists of 3 classes, of which type class $1 \mathrm{~A}$ is the most prevalent. The abnormal expression of PI3K accounts for $30 \%$ of human cancers. Overall, it is shown to serve as an oncogenic factor in the growth and development of CRC. The overexpression of phosphorylated AKT has been linked with cell division and the suppression of apoptosis in $70 \%$ of patients with CRC, along with the abnormal expression of PTEN. Akt also targets downstream protein mTOR that has been shown to favor angiogenesis and growth; research into the use of aspirin (mTOR inhibitor) has demonstrated that it inhibits CRC progression $(173,175)$.

$V E G F / V E G F R$ pathway. Angiogenesis is an essential process for the formation of blood vessels contributing crucially to cancer initiation, cell proliferation, and growth, metastasis, and invasion. Identification of vascular endothelial growth factor (VEGF-A) and the generation of monoclonal antibodies inhibitor against VEGF-A led to the direct relationship between new blood vessel formation and carcinogenesis (176). Various pro-angiogenic and anti-angiogenic factors regulate angiogenesis like VEGF, FGF, TGF- $\alpha$, TGF- $\beta$, PDGF, and angiopoietins which are released from the tumor microenvironment (177-179). The VEGF family of proteins is comprised of 5 proteins namely, VEGF-A, B, C, D and placental growth factor (PIGF). These proteins bind to VEGFR: VEGFR1, VEGFR2 and VEGFR3, a type of receptor tyrosine kinases on endothelial cells. There are 2 non-tyrosine kinase co-receptors, neuropilin-1 (NP-1) and NP-2. The diverse network between VEGF and VEGFR, VEGF-A, VEGF-B, and PIGF mainly 
contribute to angiogenesis. However, VEGF-C and VEGF-D predominantly contribute to lymph angiogenesis. VEGF-A and VEGF-B prominently bind to endothelial cells and on some non-endothelial cells via VEGFR-1 and -2 (180). VEGFR-3 is expressed on endothelial lymphatic cells and bind to VEGF-C and D with increased affinity (181).

VEGFR-1 belongs to receptor tyrosine kinase family protein known to be expressed on endothelial cells, inflammatory cells and tumor cells. VEGFR-1 regulates mainly differentiation and cell migration of endothelial cells and promotes epithelial cell differentiation during the early angiogenic event; however, it has an insignificant role in cell proliferation $(182,183)$. Furthermore, VEGFR-1 activation mediates the activation of several downstream pathways, such as PI3K/AKT/MAPK/ERK in inflammatory cells, resulting in the upregulation of inflammatory cytokine and interleukin (IL) production, such as TNF $\alpha$, IL-1 $\beta$, IL-6 and IL-8, leading to cell migration. VEGFR-1 function is still unknown and mainly plays a regulatory role in the angiogenesis process. VEGFR-2 is a 200-230 kDa protein reported in its involvement in vascular formation. VEGFR-2 is mainly expressed in blood and lymphatic epithelial cells (183). VEGF-A binds to VEGFR-2 leads to activation of VEGFR-2 resulting in the activation of several downstream pathways, such as RAS/RAF/ERK/MAPK and PLC $\gamma$ which promotes cell growth. The activation of VEGFR-2 also activates PI3K-AKT signaling, leading to the regulation of cell death $(177-180,184)$. The binding of VEGF-C and -D to VEGFR-3 results in lymphatic vessel formation $(185,186)$. Activated VEGFR-3 activates RAS-MAPK-ERK and PI3K-AKT/PKB pathways leading to differentiation, proliferation, survival, and migration of lymphatic endothelial cells (185-187). There is sufficient evidence to indicate that VEGF levels and VEGFR activity are elevated and considered to be associated with a poor prognosis in CRC (188). Elevated levels of VEGF are reported in the early and late advanced stages of CRC $(189,190)$. The interaction between VEGF-VEGFR is regulated by K-RAS mutation, p53, Cox 2 and hypoxia resulting in cell growth and migration in CRC (190-193). The pro-angiogenic function of this VEGF/VEGFR complex is critical at the primary site of tumor enhancing progression and migration and at the metastatic site for new vessel formation to promote cancer growth and survival. Targeting this complex with anti-VEGF or anti-VEGFR therapy may result in the depletion of tumor formation and metastasis.

HGF/cMET pathway. HGF and cMET play an essential role in proliferation, survival, drug resistance and metastasis (194-198). HGF is the only ligand known for MET receptor tyrosine kinase and is secreted from mesenchymal tissues. An increased expression of HGF in tissue and serum is related to a poor prognosis in various solid tumors of the breast and gastrointestinal tumors (199-201). Patients with CRC with advanced disease symptoms are reported to have higher levels of serum $\operatorname{HGF}(202,203)$. MET belongs to the transmembrane receptor family known to express in hepatocytes, normal and malignant epithelial and endothelial cells, neural cells and hematopoietic cells (204-206). MET has been reported to be overexpressed in various malignant tumors, such as hepatocellular carcinoma, lung, breast, thyroid, kidney, gastric cancer and CRC (207-213). Several studies have demonstrated elevated levels of MET mRNA and protein in CRC during tumor progression and metastasis (214-216). HGF binding to MET receptor leads to the activation of MET signaling, which initiates various downstream signaling pathways, such as MAPK-ERK, PI3K-AKT, JAK-STAT and NF- $\kappa B$, resulting in the regulation of hematopoiesis, wound healing and organ regeneration (195-200). Aberrant HGF-MET axes are comprised of gene amplification, overexpression, mutation, and ligand-mediated auto and paracrine signaling during oncogenesis (217). Other factors also modulate the HGF/MET pathway. Recently, it has been reported that a novel gene metastasis-associated in colon cancer 1 (MACC1) is a crucial player of HGF-MET signaling and regulates cancer progression and CRC metastasis (218). Increased levels of MACC1 have been observed in primary and metastatic CRC tissues. HGF induces the translocation of MACC1 from the cell membrane into the nucleus and binds to MET promoter, leading to an increased MET expression. The MET signaling pathway is also regulated by crosstalk with receptor tyrosine kinases mainly EGFR. MET and EGFR are both known to be overexpressed in CRC (219). The individual blocking of MET or EGFR has little effect on downstream ERK/PI3K activation due to the compensatory mechanism. Targeting both receptors by combined therapy results in the abrogation of the downstream pathway (220-222).

Immune checkpoint pathway. Recent data suggest that targeting immune-recognition and response may be effective in eradicating cancer cells. This strategy includes malignant tumors having different genetic and epigenetic signatures that may be identified and attacked by the host immune system expressing unique antigens. This process consists of many steps, such as $\mathrm{T}$ cell binding to MHC molecules presented by antigen-presenting cells (APCs). The next step involves signals mediated by co-stimulatory or inhibitory receptors that play a critical role in the $\mathrm{T}$ cells activation and tolerance $(223,224)$. This dual-check mechanism is essential for avoiding excessive immune response in a normal scenario and attack diseased cells (225). The process of tumor cells evading host immune recognition and response is referred to as the immune escape and has been mentioned in cancer (226). Immune escape results from immunosuppressive factors, such as TGF- $\beta$ of $T_{\text {reg }}$ cells and IL-6 regulatory cells, or the loss of immunogenicity by the inhibition of MHC-1 (227). The activation of co-inhibitory receptors, also known as immune checkpoint receptors present on the surface of $\mathrm{T}$ cells, leads to cancer-mediated $\mathrm{T}$ cell inactivation. The immune checkpoint receptors expressed on the surface of $\mathrm{T}$ cells comprise of programmed death-1 (PD-1) and cytotoxic $\mathrm{T}$ lymphocyte antigen 4 (CTLA-4). Ligands for these receptors are known as PD-L1 and PD-L2 expressed on cancer, stromal and immune cells (228). Wang et al reported elevated levels of PD-L1 in metastatic CRC as compared to primary CRC, allowing its targeting with an immune response (229). High levels of $\mathrm{T}_{\mathrm{reg}}$ cells have been found in CRC tissue as compared to adjacent normal tissue. These $\mathrm{T}_{\text {reg }}$ cells are known to express PD-1 and are crucial to the immune response to CRC (230). 
JAK/STAT signaling pathway. The 4 types of Janus kinase proteins (JAKs) include JAK1-3 and TYK2 that interact with cytokine receptors present in the colon. Although they are associated with different cytokine receptors, they have a common mechanism of the intracellular pathway, including signal transducer and activator of transcription (STAT) protein. Upon ligand-binding and physiological transformation, the associated JAKs of the cytokine receptor autophosphorylate and proceed to phosphorylate specific residues on the receptors that act as docking sites for STAT proteins. Associated JAK proteins further phosphorylate these STAT proteins, causing their dissociation and dimer formation. These dimers translocate to the nucleus, identifying and binding to gamma activated sequence (GAS) elements, causing pro-inflammatory gene expression and transcription and playing a role in the pathogenesis of inflammatory bowel disease (IBD). Drugs developed to inhibit the functioning of JAK proteins bind and prevent their phosphorylation, effectively blocking the pathway. JAK protein can also signal PI3K protein (Akt pathway) and Ras protein (MAPK pathway) (172).

TGF- $\beta$ signaling pathway. The TGF- $\beta$ pathway plays a role in cell growth, division and adhesion. It also stimulates apoptosis and cellular differentiation. Its downstream targets include important cell cycle checkpoint genes (p21, p27 and p15) that trigger growth. TGF- $\beta$ receptors occur as transmembrane heterodimers (type 1 and 2) with kinase domains (KDs) present in the intracellular part. Upon ligand binding, 2 of these heterodimers come together to form a complex through receptor dimerization. The KDs are activated through phosphorylation and further activate SMAD proteins present in the cytosol. SMAD2 and SMAD3 form phosphorylated heterodimers. This complex, joined by co-factor SMAD4, forms a heterotrimer. The heterotrimers then translocate into the nucleus and bind to TGF- $\beta$ target genes and initiate transcription. TGF- $\beta$ is known to function as a tumor suppressor, normally controlling cell division and the death of epithelial cells of the colon. CRC cells lose TGF- $\beta$, thereby resisting growth inhibition. However, in the later stages of CRC, TGF- $\beta$ expression is increased and influences epithelia-to-mesenchymal transition (EMT), and as a result, increases invasion and cell migration thus subduing the normal cellular immune response. Mutations in SMAD4 have also been reported in cases of juvenile polyposis (172-175).

Notch signaling pathway. The Notch signaling pathway occurs intercellularly and is highly conserved. Mammals possess 4 types of notch receptors (Notch 1-4). Ligands are of 2 types, the Jagged protein family (JAG 1 and 2) and the Delta-like protein family (DLL 1, 3, and 4). A Notch receptor has 3 components, namely the notch extracellular domain (binds to the ligand), Notch intracellular domain (NICD) and the transmembrane component. Ligand activation of DLL or JAG proteins on the 'sending' cell occurs through ubiquitination by a mind bomb protein (MIB). The activated ligand then binds to the extracellular component of the notch receptor. A disintegrin and metalloproteinase (ADAM protease) cleaves the extracellular domain of the notch receptor (S2 cleavage). Subsequently, another protease, secretase gamma, cleaves NICD causing it to dissociate from the transmembrane domain of the receptor
(S3 cleavage). NICD, now free to move in the cytosol, binds to and activates the CSL transcription factor (suppressor of the hairless) that forms a complex with co-activators MAML (mastermind-like proteins), and p300. The complex translocates into the nucleus where the p300 acts as a histone acetylase, causing the activation of transcription factors (ex-HES1) and the transcription of notch-target genes (example-MYC, p21). The downregulation of the pathway may occur by a ubiquitin ligase, f-box/WD-40 repeat-containing protein 7 (FBW7) that ubiquitinates NICD causing its proteasomal degradation. The overexpression of Notch-associated proteins and ligands (JAG, HES1, NICD, etc.) has been reported in CRC. Cell cycle and apoptotic regulation of target genes (p21 and PUMA genes) enhance the severity of CRC through Notch signaling. The pathway also influences CRC resistance to chemotherapeutic drugs (172-175,231).

SHH signaling pathway. The SHH signaling pathway is essential for the regeneration and differentiation of epithelial cells present in adult colons. Hedgehog ( $\mathrm{Hh})$ ligands produced in the endoplasmic reticulum of secretory cells are released through a membrane protein known as Dispatch. In a paracrine-type signaling event, these $\mathrm{Hh}$ molecules bind to Patched (Ptc) protein present in neighboring cell(s) thereby, inhibiting its function. Upon the inhibitory action of the Ptc molecule, the smoothened (Smo) protein molecule (previously inhibited by Ptc) is activated. The Smo protein present in the primary cilia of the intestine regulates the action of the 3 intracellular Gli proteins (Gli-1, Gli-2 and Gli-3). It releases Gli-2 (transcriptional activator) from the suppressor complex composed of Costal-2, Fused kinase $(\mathrm{Fu})$ and $\mathrm{SuFu}$ (suppressor of fused), thereby, activating it. This Gli-2 then acts upon and phosphorylates the transcription factor, Gli-1, that translocates to the nucleus and acts upon SHH-target genes. Smo protein also acts upon and inhibits the function of Gli-3 (a transcriptional inhibitor). In CRC tissues, it is noted that the levels of the proteins $\mathrm{SHH}, \mathrm{Smo}$ and Gli1 are uncharacteristically high (175). A previous study also reported that the subcutaneous transplantation of speckle-type POZ protein (SPOP) reduced the rate of tumor growth (in BALB/c nude mice) and increased apoptosis (in HCT116 cells) (232). In CRC, SPOP is shown to degrade Gli2 by ubiquitinating it (172). The arbitrary regulation of the signaling pathway, either by a mutation in Ptc (loss of function) or a mutation in Smo (gain of function), can lead to colon cancer development (233).

Hippo signaling pathway. The Hippo signaling pathway controls cell proliferation, homeostasis and regeneration (Fig. 4). The main transcriptional regulator of the pathway is Yes-associated protein 1 (YAP). YAP and its homolog, PDZ-binding domain taffazin (TAZ) regulate the Hippo pathway. Upon the initiation of the pathway, the activation and phosphorylation of first, mammalian Ste20-like kinases 1/2 (MST1/2), and subsequently large tumor suppressor $1 / 2$ (LATS1/2) occurs. LATS1/2, in turn, phosphorylates YAP/TAZ, resulting in its removal from the nucleus into the cytoplasm where it undergoes ubiquitin-mediated protein degradation. An abnormally high level of YAP/TAZ protein has been reported in solid tumors and amplifies the frequency of tumors $(174,234)$. 


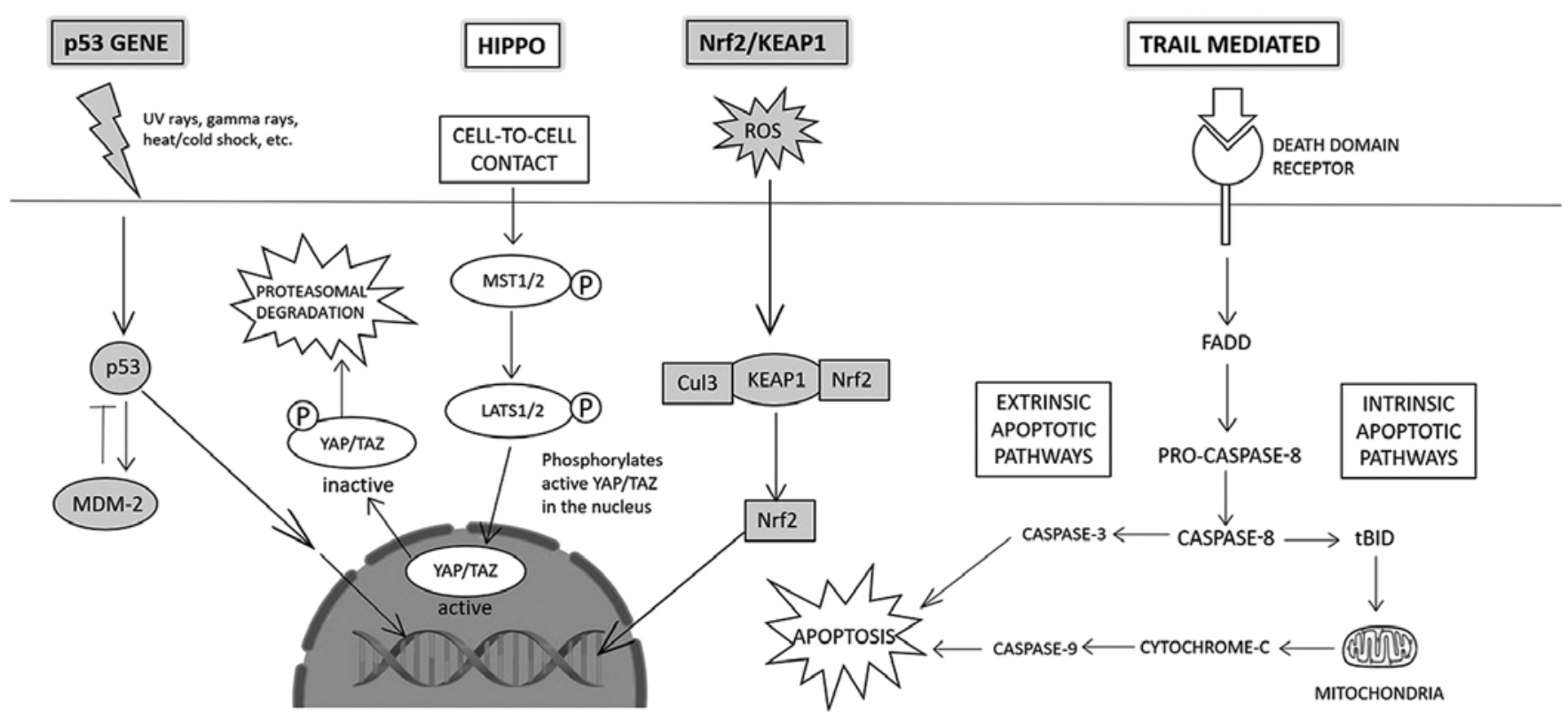

Figure 4. (Left to right) the p53 signaling pathway is activated in response to external stress (UV rays, hypoxia, etc.) and functions to repair DNA damage; the Hippo signaling pathway controls cellular homeostasis and proliferation; the Nrf2/KEAP1 signaling pathway is activated in response to ROS that damage cellular components; the TRAIL-mediated signaling pathway initiates extrinsic and intrinsic apoptosis of cells.

KEAP1/Nrf2 signaling pathway. Reactive oxygen species (ROS) cause oxidative damage to cells and are linked to CRC (Fig. 4). In response to the fatal effects of oxidative stress, the cell releases antioxidant and detoxification genes, such as NF-E2-related factor 2 (Nrf2). A Cap-n-collar transcription factor, Nrf2 identifies antioxidant response elements on target gene promoters and combats free-radical damage (by carcinogens, inflammation, etc.). Normally, Nrf2 is confined to the cytosol by Kelch-like ECH associated protein 1 (Keap1). Keap1 acts as a linker protein between Nrf2 and Cul3-based E3-ubiquitin ligase complex, causing ubiquitination of Nrf2 and its subsequent proteasomal degradation. Under conditions of oxidative stress, antioxidant response elements induce separation of Nrf2 and Keap1, leading to its nuclear transportation. There, Nrf2 undergoes dimerization and interacts with small musculoaponeurotic fibrosarcoma (Maf) proteins initiating the attachment of Nrf2 with antioxidant response elements, initiating transcriptional activation of target genes (174). The Nrf2/Keap1 pathway can help regulate the chemopreventive effects of various drugs for the treatment of CRC (174).

p53 gene-mediated signaling pathway. p53 plays an important role in maintaining the integrity of cellular processes and genetic material. It is a well-known tumor suppressor and spearheads repair and cellular apoptosis depending upon the extent of DNA damage (Fig. 4). Secreted in response to external stress such as UV rays, and hypoxia, p53 has a short half-life in the cell and is directed by a fool-proof regulatory system. Nicks or mutations caused due to external stress stimuli result in activation of the ataxia-telangiectasia mutated (ATM) protein kinase CHK2, whose absence can delay the action of $\mathrm{p} 53$. The activation of the p53 gene also results in the production of mouse double minute 2 homolog (MDM-2), an E-3 ubiquitin ligase. MDM-2 is a negative regulator that degrades the p53 gene by ubiquitinating it, thus setting up a self-governing 'loop' to maintain the p53 level in the cell. Oncogenic events can lead to the transcription of the p19 alternate reading frame (ARF) protein that inhibits the functioning of MDM-2, thus, failing to regulate p53 levels in the cell. Mutations in the p53 gene and aberrant function lead to a loss of cellular checkpoints and programmed cell death, thereby compromising genetic integrity (174). Mutations also encourage EMT, and the formation of adenomatous polyps, eventually conferring malignancy, i.e., CRC. It has also been noted that $80 \%$ of p53 mutations in CRC cases stemmed from missense mutations, largely in exons 4-8 (172).

TNF-related apoptosis-inducing ligand (TRAIL)-mediated signaling pathway. The TRAIL-mediated signaling pathway is a candidate for anticancer therapy by selectively targeting cancer cells (Fig. 4). TRAIL receptors span the cellular membrane and act as a conduit for the extrinsic apoptotic pathway. TRAIL ligand binds to specific death domain receptors DR4/DR5 which augments the association of Fas-associated protein with death domain (FADD), an adaptor protein. FADD activates pro-caspase 8 , initiating the apoptotic pathway (through recruitment of various caspases initiating the extrinsic, and cytochrome-c initiating the intrinsic apoptotic pathway) (172).

\section{Crosstalk among various pathways}

The majority of signaling pathways interact to maintain cellular homeostasis in healthy cells (Fig. 5). For example, the non-canonical TGF- $\beta$ signaling pathway induces the MAPK and PI3K signaling pathways, both of which otherwise activate upon ligand-binding on receptor tyrosine kinase (EGFR). TGF- $\beta$ and its tumor-suppressive activity can also be inhibited by interaction with the mutant p53 complex. Another example 


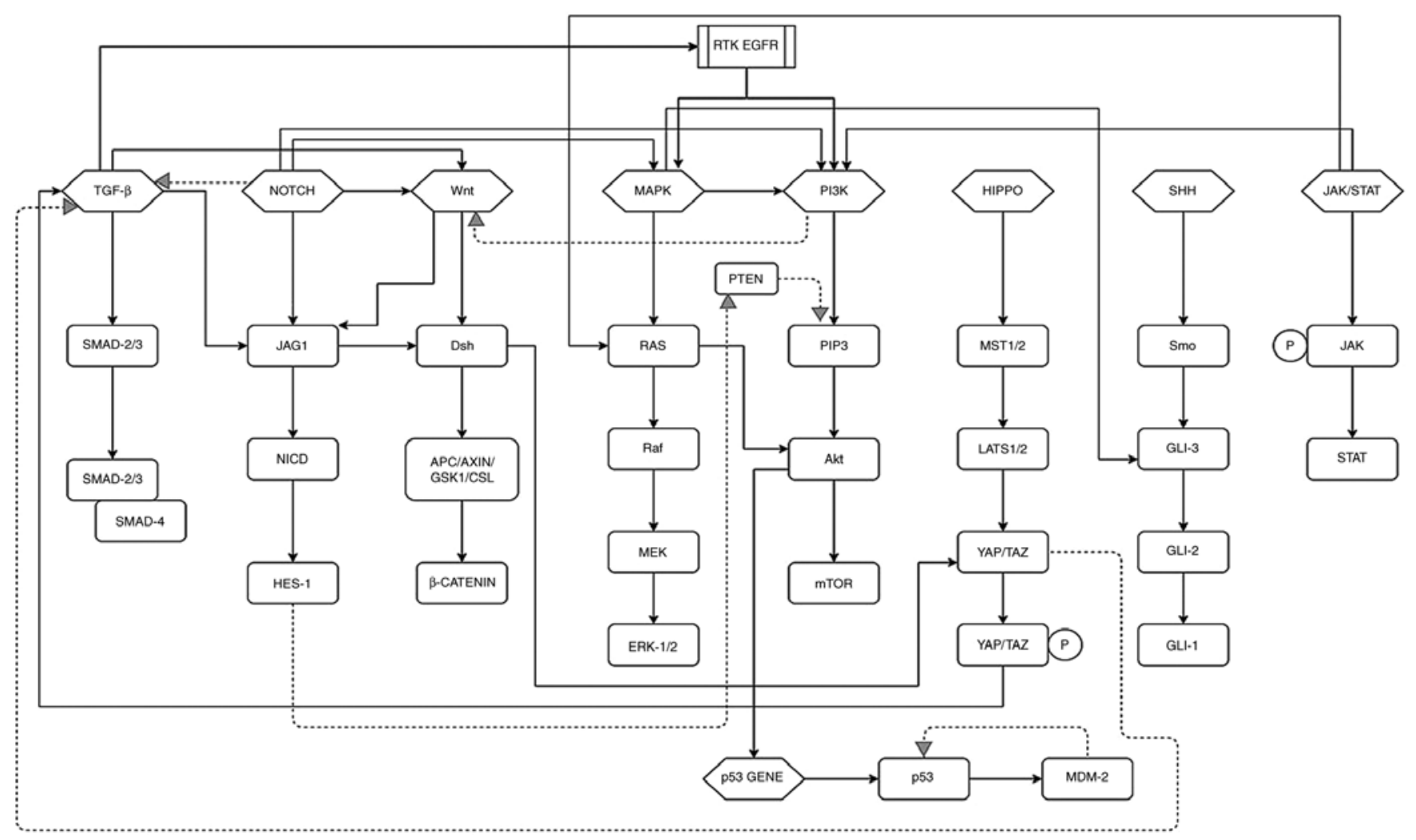

Figure 5. The various canonical and non-canonical signaling pathways interact with one another through downstream regulation or by inhibiting or enhancing the working of a gene/pathway. A few of these interactions have been shown in the figure inhibiting (dashed arrows) or inducing (black arrows) the working of the various components of the signaling pathways.

is the JAK/STAT signaling pathway. Following autophosphorylation, it can activate Ras protein and ERK-1/2 (MAPK pathway) and AKT in downstream signaling.

The Notch signaling pathway may interact with various other pathways (231); the Wnt pathway is influenced by the binding of NICD to the Dsh1 protein (173). The Wnt pathway can activate Jag1 and amplify Notch signaling initiating CRC. During colorectal oncogenesis, Notch activates the EGFR and PI3K pathways (173). PI3K is activated through the inhibition of PTEN by HES1 (a Notch transcription factor). It can also suppress the cell growth inhibiting-function of the TGF- $\beta$ pathway (173). TGF- $\beta$ can non-canonically activate various pathways, such as PI3K, MAPK/ERK (235), Wnt (236) and Notch (237). In CRC, TGF- $\beta$ activates Jag1 and leads to the overexpression of Notch signaling. K-Ras from the MAPK pathway can interact with and activate the catalytic subunit p110 of PI3K. Carcinogenesis results in the aberrant activity of cell cycle regulators. The upregulation of cyclin D1 production and an increase in cellular $\beta$-catenin levels is a result of K-Ras and APC mutations and activation. The APC/axin/GSK3 $\beta$ complex from the Wnt/ $\beta$-catenin pathway and SMAD7 can alter the function of SMAD proteins of the TGF- $\beta$ pathway, resulting in delayed apoptosis and metastasis, and an increased cell growth and division. Studies have indicated that the Dsh protein of the Wnt pathway influences the translocation of YAP protein (Hippo pathway) by close contact inhibition of E-cadherin $(238,239)$.

The Hippo signaling pathway interacts with the TGF- $\beta$ pathway in a positive and negative regulatory manner, depending upon the circumstances. TAZ protein can bind to the SMAD2/3-SMAD4 complex and maintain its accumulation in the nucleus (boosting TGF- $\beta$ pathway), or phosphorylated TAZ protein can prevent SMAD 2/SMAD 4 nuclear build-up (repressing TGF- $\beta$ signaling).

The activation of the MAPK signaling pathway through RTK can influence Gli protein activity (of the SHH pathway) in a Smo-independent manner. The co-expression of EGF and Gli protein activates both pathways and promotes carcinogenic transformation. Smo-independent and PI3K-dependent Gli factor activation, occurring due to AKT-associated prevention of proteasomal degradation of Gli2, is prevalent in colon cancer. Amplification of Gli1 activity through ribosomal S6 kinases is also influenced by the PI3K pathway. The non-canonical SHH pathway promotes CRC cell survival via the Wnt signaling pathway, and EMT and tumor invasion via the TGF- $\beta$ signaling pathway $(240,241)$.

\section{Current chemotherapeutics for colorectal cancer}

5-Fluorouracil (5FU) is the backbone of chemotherapy with good activity against CRC (242). Folinic acid (FA, leucovorin) was then also added to the regimen, that achieves a median overall survival of approximately 8-9 months and has become the standard treatment for metastatic CRC (mCRC) $(243,244)$. Oxaliplatin (platinum analogue) and irinotecan (topoisomerase inhibitor) were added to the backbone of 5FU/FA. Combination chemotherapy has demonstrated a higher response rate and a better overall survival of 14-18 months, as well as a 
Table II. Targeted therapeutics for the EGFR/RAS/MAPK pathway.

\begin{tabular}{|c|c|c|}
\hline Inhibitor & Target & Function \\
\hline Cetuximab & EGFR & EGFR inhibitor \\
\hline Panitumumab & EGFR & EGFR inhibitor \\
\hline Geftinib & EGFR & EGFR inhibitor \\
\hline Sorafenib & RAF & Tyrosine kinase inhibitor \\
\hline Pertuzumab & Her2 & Monoclonal antibody \\
\hline Erlotinib & EGFR & Receptor Tyrosine kinase inhibitor \\
\hline Lapatinib & EGFR, Her2 & Tyrosine kinase inhibitor \\
\hline Dacomitinib & EGFR & Irreversible EGFR inhibitor \\
\hline Canertinib (CI-1033) & EGFR, Her2, ErbB-4 & Irreversible tyrosine kinase inhibitor \\
\hline Sunitinib & RTK2 & Receptor Tyrosine kinase inhibitor \\
\hline PD158780 & EGFR, ErbB-3, ErbB-4 & Tyrosine kinase inhibitor \\
\hline SCH772984 & ERK $1 / 2$ & ERK1/2 inhibitor \\
\hline VX-11e & ERK2 & ERK2 inhibitor \\
\hline Binimetinib & MEK1/2 & MEK1/2 inhibitor \\
\hline Trastuzumab & HER2/neu & HER2 inhibitor \\
\hline EMD72000 & EGFR & Monoclonal antibody for EGFR \\
\hline Vemurafenib & BRAF-V600E & BRAF-V600E inhibitor \\
\hline Dabrafenib & BRAF-V600E, C-RAF, BRAF & BRAF-V600E inhibitor \\
\hline Encorafenib & BRAF-V600E & RAF inhibitor \\
\hline Selumetinib & MEK1/2 & MEK1/2 inhibitor \\
\hline
\end{tabular}

progression-free survival (PFS) of 5-8 months. FOLFOX (5FU/FA and oxaliplatin) or FOLFIRI (5FU/FA and irinotecan) constitute first-line standard combination chemotherapy $(245,246)$. Both have exhibited approximately equal clinical responses with different safety profiles. A regimen containing oxaliplatin gives rise to peripheral neuropathy and irinotecan results in gastrointestinal toxicity $(247,248)$. The replacement of 5FU/FA with capecitabine (Xeloda) has been investigated with oxaliplatin (XELOX) or with irinotecan (XELIRI) resulting in similar efficacy, as the combination with 5FU/FA $(249,250)$. With the improved screening efforts, the diagnosis of patients with CRC has improved and the mortality rate has decreased due to the early detection and the success of anticancer therapies. Despite the success of current therapeutics, $40-50 \%$ of CRC cases ultimately relapse, leading to fatality due to metastasis (251). Although the treatment options for patients with CRC have improved, more effective targeting agents are required for the treatment of advanced stages of the disease. Therefore, targeted anticancer therapeutics are warranted to disrupt the dysregulated signaling pathways of CRC with a better outcome for patients.

\section{Strategies for the targeted therapy of colorectal cancer}

The idea of targeted therapy against cancer has flourished over the past 2 decades $(252,253)$. Targeted therapies block the function of certain oncoproteins and downstream pathways using monoclonal antibodies or small molecules against receptor/non-receptor tyrosine kinases. Monoclonal antibodies are the main candidates in targeted therapies that target surface receptors and membrane-bound factors outside the cancer cells $(253,254)$. Monoclonal antibodies can recognize and bind cancer cells directly, regulating downstream pathways and leading to the inhibition of cell cycle advancement and subsequent cell death. Immune cells are also targeted by monoclonal antibodies to manipulate the immune system to attack and discard cancer cells. Small molecules are robustly developed that work mostly inside the cells to target receptor and non-receptor tyrosine kinases, thereby blocking cancer cell growth and inducing cell death (255). These targeted treatments lead to the inhibition of the differentiation, proliferation, invasion and migration of cancer cells. These therapies also act on the tumor microenvironment, resulting in a decrease in angiogenesis and rendering immune cells more alert for stronger surveillance and attack.

Monoclonal antibody against EGFR (cetuximab) was the first targeted therapy approved by the FDA in 2004 for the treatment of CRC. In the same year, another monoclonal antibody targeting VEGF-A (bevacizumab) was approved for the treatment of CRC (256). Ideal sites for targeted therapy are present in the dysregulated pathway of TGF- $\beta /$ SMAD, Wnt/ $\beta$-catenin, EGFR, VEGFR/VEGRR, Notch, Hedgehog activating PI3K/AKT and RAS/RAF pathways (257). The intricate network of downstream signaling pathways and the crosstalk among these renders the complete blocking of specific biological interactions complex and difficult.

The dysregulation of various signaling pathways leads to $\mathrm{CRC}$ initiation, progression and migration. The activation of signaling pathways leads to the acquisition of a malignant phenotype. One novel approach could be to use specific inhibitors targeting these pathways. Small molecule inhibitors-based anticancer therapeutics provide an excellent opportunity for 
Table III. Targeting the PI3K-AKT pathway.

\begin{tabular}{lll}
\hline Inhibitor & \multicolumn{1}{c}{ Target } & Function \\
\hline GSK690693 & AKT & AKT Inhibitor \\
SF-1126 & PI3K, mTOR & PI3K pathway inhibitor \\
AZD8055 & mTOR & mTOR inhibitor \\
Everolimus & mTOR & mTOR inhibitor \\
BGT226 & mTOR, PI3K $\alpha / \beta / \gamma$ & PI3K/mTOR inhibitor \\
CAL-101 & P110 $/ \delta$ & P110 inhibitor \\
Perifosine & AKT & AKT inhibitor \\
MK2206 & AKT & AKT inhibitor \\
OSI027 & mTOR & mTOR kinase inhibitor \\
Alpelisib & PI3K $\alpha$ & PI3K $\alpha$ inhibitor \\
\hline
\end{tabular}

Table IV. Targeting the TGF- $\beta /$ Wnt- $\beta$-catenin/Notch pathway.

\begin{tabular}{lll}
\hline Inhibitor & \multicolumn{1}{c}{ Target } & \multicolumn{1}{c}{ Function } \\
\hline LY2109761 & TGFBRI/II & TGF- $\beta$ receptor inhibitor \\
AP15012 & TGFb1 & Antisense molecules \\
AP11014 & TGFb & Antisense molecules \\
PNU-74654 & Wnt/ $\beta$-catenin & Wnt- $\beta$-catenin inhibitor \\
BC2059 & $\beta$-catenin & $\beta$-catenin inhibitor \\
Sulindac & Dishevelled & Blocks PDZ domain of Dishevelled \\
GSI34 & $\gamma$ Secretase & $\gamma$ Secretase inhibitor \\
RO4929097 & $\gamma$ Secretase & $\gamma$ Secretase inhibitor \\
DAPT & $\gamma$ Secretase & $\gamma$ Secretase inhibitor \\
Dibenzazepine & $\gamma$ Secretase & $\gamma$ Secretase inhibitor \\
LY411575 & $\gamma$ Secretase & $\gamma$ Secretase inhibitor \\
\hline
\end{tabular}

scientists to navigate various aspects of cell growth, cell cycle, cell proliferation to gene expression, and protein-protein interaction network. The EGFR/MAPK pathway has been targeted by small molecules and antibodies. Targeting the EGFR pathway and related factors has been achieved by the use of monoclonal antibodies, such as anti-EGFR and tyrosine kinase inhibitors (TKIs) (Table II). Small molecules targeting EGFR, Ras and Raf are known to interfere with the MAPK signaling pathway. EGFR antibodies are also known to block MAPK signaling. For metastatic colorectal cancer, EGFR inhibitors are a valuable therapeutic option. Monoclonal antibodies for EGFR (cetuximab or panitumumab) in addition to chemotherapy are effective for mCRC patients harbouring wild type RAS and BRAF (258). Previous research has reported different inhibitors for the targeting of PI3K signaling (259), namely: i) PI3K inhibitors; ii) dual inhibitors of PI3K and mTOR; iii) AKT inhibitors; and iv) mTOR inhibitors. A summary of some of the inhibitors targeting the PI3K/AKT pathway in CRC is presented in Table III.

Targeting the TGF- $\beta$ pathway has been achieved by specifically targeting the ligand, ligand-receptor complex and the intracellular levels of TGF- $\beta$. Anti-TGF- $\beta$ therapy holds promise, as pre-clinical studies and clinical trials have indicated (260). TGF- $\beta$ synthesis has been blocked using antisense molecules in CRC. TGF- $\beta$-R1 and R2 kinase is known to be blocked by a small molecule (LY2109761) (261). The Wnt signaling pathway is targeted by different inhibitors ranging from small molecules, peptides and antibodies. In total, 4 types of Wnt inhibitors have been developed based on specific targets: i) Generic; ii) $\beta$-catenin destruction complex; iii) Wnt-receptor complex; and iv) nuclear-transcription factor complexes (171). It has been found that targeting notch receptor and notch ligands using siRNA results in more effective therapeutics (262). Antibodies against Notch ligands and receptors have been reported to be effective in blocking the Notch pathway. Anti-Notch-1, -2/3 and anti-DLL4 are in different stages of clinical trials (263) (Table IV).

JAK-STAT pathway inhibition has been achieved using various approaches. The small molecule inhibitor of this pathway, such asJAK inhibitors are in clinical trials for gastrointestinal disorders, including ulcerative colitis (UC) (NCT01959282, NCT03006068, NCT02914535, NCT02914522, NCT02819635) and Crohn's disease (CD) (NCT03345836, NCT02782663, NCT03345849, NCT02914600, NCT02914561) (264). The anti-IL-6-R antibody is known to inhibit IL-6R function and is in the preclinical stage of development. A JAK inhibitor (AZD1480) and STAT3 inhibitors, such as Trichostatin A and bufalin have also been 
Table V. Targeting the VEGF/VEGFR pathway.

\begin{tabular}{lll}
\hline Inhibitor & \multicolumn{1}{c}{ Target } & Function \\
\hline Bevacizumab & VEGF-A & Monoclonal antibody for VEGF-A \\
Aflibercept & VEGF-A, -B & Ligand trap for VEGF-A, -B \\
Ramucirumab & VEGFR-2 & Monoclonal antibody for VEGFR-2 \\
Vanucizumab & VEGF-A/angiopoetin-2 & Monoclonal antibody for VEGF-A \\
Sorafenib & VEGFR & Tyrosine kinase inhibitor \\
Fruquintinib & Pan-VEGFR & Tyrosine kinase inhibitor \\
Famitinib & VEGFR-2/-3/PDGFR & Tyrosine kinase inhibitor \\
Brivanib & VEGFR-2/FGFR & Tyrosine kinase inhibitor \\
Nintedanib & VEGFR & Tyrosine kinase inhibitor \\
Sunitinib & Pan-VEGFR & Tyrosine kinase inhibitor \\
Axitinib & Pan-VEGFR & Tyrosine kinase inhibitor \\
Tanibirimab & VEGFR2 & Monoclonal antibody \\
Regorafenib & VEGFR/FGFR/PDGFR/BRAF & Tyrosine kinase inhibitor
\end{tabular}

Table VI. Targeting the HGF/MET pathway.

\begin{tabular}{llr}
\hline Inhibitor & Target & Function \\
\hline ABT-700 & HGF & Humanized antibody \\
Rilotumumab & HGF & Monoclonal antibody \\
Onartuzumab & MET & Monoclonal antibody \\
DN-30 & MET & Monoclonal antibody \\
AMG337 & MET & Tyrosine kinase inhibitor \\
Tivatinib & MET & Tyrosine kinase inhibitor \\
Savolitinib & MET & Tyrosine kinase inhibitor \\
Capmatinib & MET & Tyrosine kinase inhibitor \\
Foretinib & MET/VEGFR & Tyrosine kinase inhibitor \\
Golvatinib & MET/VEGFR & Tyrosine kinase inhibitor \\
\hline
\end{tabular}

Table VII. Targeting immune checkpoint receptor pathway in colorectal cancer.

\begin{tabular}{llr}
\hline Inhibitor & Target & Function \\
\hline Pembrolizumab & PD-1 & Monoclonal antibody \\
Nivolumab & PD-1 & Monoclonal antibody \\
Avelumab & PD-1/PDL-1 & Monoclonal antibody \\
Atezolizumab & PD-1/PDL-1 & Monoclonal antibody \\
Durvalumab & PD-1/PDL-1 & Monoclonal antibody \\
SHR-1210 & PD-1/PDL-1 & Monoclonal antibody \\
PDR-001 & PD-1/PDL-1 & Monoclonal antibody \\
TSR-033 & PD-1/PDL-1 & Monoclonal antibody \\
ONC-392 & CTLA-4 & Monoclonal antibody \\
Tremelimumab & CTLA-4 & Monoclonal antibody \\
Camrelizumab & PD-1/PDL-1 & Monoclonal antibody
\end{tabular}

shown to be successful in the inhibition of the JAK/STAT pathway (265). The association between CRC and hedgehog (Hh) signaling remains inconclusive; its inhibitors have been used in in vitro and in vivo studies (266). The most common $\mathrm{Hh}$ inhibitor is cyclopamine. Wu et al reported the efficacy of this inhibitor in the treatment of CRC in vitro (267). It has 
also been demonstrated that cyclopamine can inhibit proliferation and induction of apoptosis in CRC $(267,268)$. The NRF2 pathway is known to act as a 'double-edged sword', acting as an oncogene and tumor suppressor in CRC (269). Inhibitors targeting the NRF2 and Hippo pathways are still in the initial stage, paving the way for further studies. A combination of conventional chemotherapeutics with inhibitors of signaling pathways may enhance patient outcome (270).

The discovery of bevacizumab (anti-VEGF-A) and its effectiveness against CRC was a milestone in the treatment of solid tumors by blocking angiogenesis (271). It is a humanized $\mathrm{IgG}$ monoclonal antibody that improves both progression-free survival and overall survival in mCRC. FDA approved VEGF-targeted bevacizumab for the treatment of mCRC. Combining bevacizumab with the FOLFOX/FOXFIRI regimen has been shown to provide a partial significant improvement in progression-free survival and overall survival (272). Various novel agents have been reported and few have been endorsed for the treatment of CRC. Aflibercept is a ligand trap-based VEGFR-1 and -2 extracellular domain recombinant fusion protein targeting VEGF-A and VEGF-B; clinical trials have reported that it has a stronger affinity for VEGF-A (273). A TKI, regorafenib, targeting VEGFR, FGFR, PDGFR and BRAF has been approved by the FDA for the treatment of mCRC (274). Another humanized monoclonal antibody for VEGFR-2, ramucirumab, is an FDA-approved second-line treatment for mCRC (275) (Table V).

The HGF/MET pathway is known to be upregulated and therefore initiates the activation of downstream pathways, such as MAPK/ERK, PI3K/AKT and JAK/STAT in CRC. HGF/MET signaling can be blocked by antibodies and small molecules using different mechanisms (202). These small molecules act by either blocking HGF activation or inhibiting HGF binding to MET receptors and thereby inhibiting cancer cell growth. Rilotumumab, a humanized monoclonal antibody for HGF acts by neutralizing HGF binding to receptors in clinical trials. Various antibodies targeting MET have been developed that target $\mathrm{HGF}$ binding to MET, resulting in its degradation. DN-30, ABT-700 and onartuzumab have been studied in solid tumors in clinical trials. Several selective and non-selective TKIs have been investigated in clinical trials $(276,277)$ (Table VI).

Targeted therapy for immune checkpoint enhances immune surveillance and tumor suppression by blocking tumor cell escape from $\mathrm{T}$ cell recognition (278). A phase I trial of immune checkpoint targeted therapy revealed a significant response in mCRC (279). Further studies noted that a small number of patients with mCRC responded to this therapy, owing to a high mutational burden, exhibiting high levels of MSI-H and dMMR (MMR deficiency) (280-283). The first PD-1 blocker approved by the FDA in 2017 was pembrolizumab that exhibited promising efficacy in MMR-deficient CRC (284). Pembrolizumab is a humanized IgG4 antibody against PD-1 set another milestone in CRC immunotherapy (285). Another humanized monoclonal IgG4 antibody for PD-1 (nivolumab) received FDA approval for the treatment of MSI-H and dMMR mCRC in 2017 (286). Other novel PD-1/PDL-1 inhibitors have been looking promising in phase I clinical trials of CRC and other solid tumors (287) (Table VII).

\section{Conclusions}

CRC is a complex and heterogeneous disease, exhibiting multiple genetic mutations and epigenetic aberrations. Individuals with predisposing germline mutations may exhibit somatic mutation accumulation at various stages, resulting in the cell transformation from normal epithelial cells to malignant and invasive cancer. Genetic testing for MSI in Lynch syndrome has led to the targeted surveillance of at-risk family members for the prevention of CRC. Targeted EGFR and VEGF therapies have already had a better impact on the management of mCRC. A heterogeneous disease, such as CRC resulting from the activation of numerous signaling pathways, is therapeutically challenging, and cannot be targeted with a single agent. A combination of conventional therapeutics with novel inhibitors targeting dysregulated pathways is required for a better outcome. The latest discoveries have assisted researchers in improving their knowledge of CRC to an unprecedented level. In the present review, the molecular pathways and the dysregulation of signaling pathways that play an essential role in CRC initiation and progression were discussed. More extensive knowledge of CRC has been acquired, and the efficiency of the first sign of targeted therapies provides an encouraging prospect for the future management and development of more efficient markers for the treatment of CRC. The design of novel scaffolds, such as TKIs and specific inhibitors/antibodies to inhibit oncogenes and dysregulated signaling pathways is expanding. With the discovery of more targeted novel therapeutics, there is real hope that CRC can be better managed, leading to a lower disease burden in the future.

\section{Acknowledgements}

The authors are grateful to the Deanship of Scientific Research, King Saud University for funding through the Vice Deanship of Scientific Research Chairs.

\section{Funding}

No funding was received.

\section{Availability of data and materials}

Not applicable.

\section{Authors' contributions}

JKS, RA, AW and SKS conceived, drafted and wrote the manuscript. OAO and MA were involved in the critical reviewing of the manuscript. RA and SKS were involved in the revising and editing of the manuscript. All authors have read and approved the final manuscript.

\section{Ethics approval and consent to participate}

Not applicable.

\section{Patient consent for publication}

Not applicable. 


\section{Competing interests}

The authors declare that they have no competing interests.

\section{References}

1. Siegel RL, Miller KD, Goding Sauer A, Fedewa SA, Butterly LF, Anderson JC, Cercek A, Smith RA and Jemal A: Colorectal cancer statistics, 2020: CA Cancer J Clin 70: 145-164, 2020.

2. Arnold M, Sierra MS, Laversanne M, Soerjomataram I, Jemal A and Bray F: Global patterns and trends in colorectal cancer incidence and mortality. Gut 66: 683-691, 2017.

3. Fleming M, Ravula S, Tatishchev SF and Wang HL: Colorectal carcinoma: Pathologic aspects. J Gastrointest Oncol 3: 153-173, 2012.

4. Jasperson KW, Tuohy TM, Neklason DW and Burt RW: Hereditary and familial colon cancer. Gastroenterology 138 2044-2058, 2010.

5. Graff RE, Möller S, Passarelli MN, Witte JS, Skytthe A, Christensen K, Tan Q, Adami HO, Czene K, Harris JR, et al: Familial risk and heritability of colorectal cancer in the nordic twin study of cancer. Clin Gastroenterol Hepatol 15: 1256-1264, 2017.

6. Lichtenstein P, Holm NV, Verkasalo PK, Iliadou A, Kaprio J, Koskenvuo M, Pukkala E, Skytthe A and Hemminki K Environmental and heritable factors in the causation of cancer-analyses of cohorts of twins from Sweden, Denmark, and Finland. N Engl J Med 343: 78-85, 2000.

7. Keum $\mathrm{N}$ and Giovannucci E: Global burden of colorectal cancer: Emerging trends, risk factors and prevention strategies. Nat Rev Gastroenterol Hepatol 16: 713-732, 2019.

8. Ogino S and Goel A: Molecular classification and correlates in colorectal cancer. J Mol Diagn 10: 13-27, 2008

9. Grady WM and Carethers JM: Genomic and epigenetic instability in colorectal cancer pathogenesis. Gastroenterology 135 1079-1099, 2008.

10. Bakhoum SF, Silkworth WT, Nardi IK, Nicholson JM, Compton DA and Cimini D: The mitotic origin of chromosomal instability. Curr Biol 24: R148-R149, 2014.

11. Nazemalhosseini Mojarad E, Kuppen PJK, Aghdaei HA and Zali MR: The $\mathrm{CpG}$ island methylator phenotype (CIMP) in colorectal cancer. Gastroenterol Hepatol Bed Bench 6: 120-128, 2013.

12. Markowitz SD and Bertagnolli MM: Molecular origins of cancer: Molecular basis of colorectal cancer. N Engl J Med 361: 2449-2460, 2009.

13. Pawlik TM, Raut CP and Rodriguez-Bigas MA: Colorectal carcinogenesis: MSI-H versus MSI-L. Dis Markers 20: 199-206, 2004

14. Pitot HC: The molecular biology of carcinogenesis. Cancer 72 (3 Suppl): S962-S970, 1993.

15. O'Connell JB, Maggard MA and Ko CY: Colon cancer survival rates with the new American joint committee on cancer sixth edition staging. J Natl Cancer Inst 96: 1420-1425, 2004.

16. Xu W, He Y, Wang Y, Li X, Young J, Ioannidis JPA, Dunlop MG and Theodoratou E: Risk factors and risk prediction models for colorectal cancer metastasis and recurrence: An umbrella review of systematic reviews and meta-analyses of observational studies. BMC Med 18: 172, 2020

17. Jensen KH, Izarzugaza JMG, Juncker AS, Hansen RB, Hansen TF, Timshel P, Blondal T, Jensen TS, Rygaard-Hjalsted E, Mouritzen P, et al: Analysis of a gene panel for targeted sequencing of colorectal cancer samples. Oncotarget 9: 9043-9060, 2018.

18. Fearon ER and Vogelstein B: A genetic model for colorectal tumorigenesis. Cell 61: 759-767, 1990.

19. Fearon ER: Molecular genetics of colorectal cancer. Annu Rev Pathol 6: 479-507, 2011

20. Vogelstein B, Fearon ER, Hamilton SR, Kern SE, Preisinger AC, Leppert M, Nakamura Y, White R, Smits AM and Bos JL: Genetic alterations during colorectal-tumor development. N Engl J Med 319: 525-532, 1988.

21. Jass JR and Smith M: Sialic acid and epithelial differentiation in colorectal polyps and cancer-a morphological, mucin and lectin histochemical study. Pathology 24: 233-242, 1992.

22. Dekker E and IJspeert JEG: Serrated pathway: A paradigm shift in CRC prevention. Gut 67: 1751-1752, 2018.

23. East JE, Vieth M and Rex DK: Serrated lesions in colorectal cancer screening: Detection, resection, pathology and surveillance. Gut 64: 991-1000, 2015.
24. Longacre TA and Fenoglio-Preiser CM: Mixed hyperplastic adenomatous polyps/serrated adenomas. A distinct form of colorectal neoplasia. Am J Surg Pathol 14: 524-537, 1990.

25. Snover DC, Ahnen D, Burt R and Odze R: Serrated polyps of the colon and rectum and serrated ('hyperplastic') polyposis. WHO classification of tumours of the digestive system. International Agency for Research on Cancer, Lyon, pp160-165, 2010.

26. Groff RJ, Nash R and Ahnen DJ: Significance of serrated polyps of the colon. Curr Gastroenterol Rep 10: 490-498, 2008.

27. Aust DE and Baretton GB; Members of the Working Group GI-Pathology of the German Society of Pathology: Serrated polyps of the colon and rectum (hyperplastic polyps, sessile serrated adenomas, traditional serrated adenomas, and mixed polyps)-proposal for diagnostic criteria. Virchows Arch 457: 291-297, 2010.

28. Torlakovic E, Skovlund E, Snover DC, Torlakovic G and Nesland JM: Morphologic reappraisal of serrated colorectal polyps. Am J Surg Pathol 27: 65-81, 2003.

29. Goldstein NS, Bhanot P, Odish E and Hunter S: Hyperplastic-like colon polyps that preceded microsatellite-unstable adenocarcinomas. Am J Clin Pathol 119: 778-796, 2003.

30. Kim KM, Lee EJ, Kim YH, Chang DK and Odze RD: KRAS mutations in traditional serrated adenomas from Korea herald an aggressive phenotype. Am J Surg Pathol 34: 667-675, 2010.

31. International Agency for Research on Cancer (IARC): Global Cancer Observatory (GLOBOCAN). IARC, Lyon, 2018.

32. Ferlay J, Ervik M, Lam F, Colombet M, Mery L, Piñeros M, Znaor A, Soerjomataram I and Bray F: Global Cancer Observatory: Cancer Today. International Agency for Research on Cancer, Lyon, 2018.

33. Li FY and Lai MD: Colorectal cancer, one entity or three. J Zhejiang Univ Sci B 10: 219-229, 2009.

34. Murphy N, Ward HA, Jenab M, Rothwell JA, Boutron-Ruault MC Carbonnel F, Kvaskoff M, Kaaks R, Kühn T, Boeing H, et al: Heterogeneity of colorectal cancer risk factors by anatomical subsite in 10 european countries: A multinational cohort study. Clin Gastroenterol Hepatol 17: 1323-1331.e6, 2019.

35. Yang L, Xiong Z, He W, Xie K, Liu S, Kong P, Jiang C, Guo G and Xia L: Proximal shift of colorectal cancer with increasing age in different ethnicities. Cancer Manag Res 10: 2663-2673, 2018.

36. Murphy G, Devesa SS, Cross AJ, Inskip PD, McGlynn KA and Cook MB: Sex disparities in colorectal cancer incidence by anatomic subsite, race and age. Int J Cancer 128: 1668-1675, 2011.

37. Shin A, Kim KZ, Jung KW, Park S, Won YJ, Kim J, Kim DY and Oh JH: Increasing trend of colorectal cancer incidence in Korea, 1999-2009. Cancer Res Treat 44: 219-226, 2012.

38. Rawla P, Sunkara T and Barsouk A: Epidemiology of colorectal cancer: Incidence, mortality, survival, and risk factors. Prz Gastroenterol 14: 89-103, 2019.

39. Win AK, Jenkins MA, Dowty JG, Antoniou AC, Lee A, Giles GG, Buchanan DD, Clendenning M, Rosty C, Ahnen DJ, et al: Prevalence and penetrance of major genes and polygenes for colorectal cancer. Cancer Epidemiol Biomarkers Prev 26: 404-412, 2017.

40. Aaltonen LA, Peltomäki P, Leach FS, Sistonen P, Pylkkänen L, Mecklin JP, Järvinen H, Powell SM, Jen J, Hamilton SR, et al: Clues to the pathogenesis of familial colorectal cancer. Science 260: 812-416, 1993

41. Ionov Y, Peinado MA, Malkhosyan S, Shibata D and Perucho M: Ubiquitous somatic mutations in simple repeated sequences reveal a new mechanism for colonic carcinogenesis. Nature 363: 558-561, 1993.

42. Thibodeau SN, Bren G and Schaid D: Microsatellite instability in cancer of the proximal colon. Science 260: 816-819, 1993.

43. Hampel H, Frankel WL, Martin E, Arnold M, Khanduja K, Kuebler P, Nakagawa H, Sotamaa K, Prior TW, Westman J, et al: Screening for the Lynch syndrome (hereditary nonpolyposis colorectal cancer). N Engl J Med 352: 1851-1860, 2005.

44. Patel SG and Ahnen DJ: Familial colon cancer syndromes: An update of a rapidly evolving field. Curr Gastroenterol Rep 14: 428-438, 2012.

45. Half E, Bercovich D and Rozen P: Familial adenomatous polyposis. Orphanet J Rare Dis 4: 22, 2009.

46. Vasen HF, Tomlinson I and Castells A: Clinical management of hereditary colorectal cancer syndromes. Nat Rev Gastroenterol Hepatol 12: 88-97, 2015.

47. Sir Michael M, Tola A, Tim B and Junshi C: World Cancer Research Fund/American Institute for Cancer Research. Food, Nutrition, Physical Activity, and the Prevention of Cancer: A Global Perspective. AICR, Washington, DC, 2007. 
48. Hofseth LJ, Hebert JR, Chanda A, Chen H, Love BL, Pena MM, Murphy EA, Sajish M, Sheth A, Buckhaults PJ and Berger FG: Early-onset colorectal cancer: Initial clues and current views. Nat Rev Gastroenterol Hepatol 17: 352-364, 2020.

49. Mauri G, Sartore-Bianchi A, Russo AG, Marsoni S, Bardelli A and Siena S: Early-onset colorectal cancer in young individuals. Mol Oncol 13: 109-131, 2019.

50. Bailey CE, Hu CY, You YN, Bednarski BK, Rodriguez-Bigas MA, Skibber JM, Cantor SB and Chang GJ: Increasing disparities in the age-related incidences of colon and rectal cancers in the United States, 1975-2010. JAMA Surg 150: 17-22, 2015.

51. Pearlman R, Frankel WL, Swanson B, Zhao W, Yilmaz A, Miller K, Bacher J, Bigley C, Nelsen L, Goodfellow PJ, et al: Ohio colorectal cancer prevention initiative study group: Prevalence and spectrum of germline cancer susceptibility gene mutations among patients with early-onset colorectal cancer. JAMA Oncol 3: 464-471, 2017.

52. Schellerer VS, Merkel S, Schumann SC, Schlabrakowski A, Förtsch T, Schildberg C, Hohenberger W and Croner RS: Despite aggressive histopathology survival is not impaired in young patients with colorectal cancer: CRC in patients under 50 years of age. Int J Colorectal Dis 27: 71-79, 2012.

53. Wang MJ, Ping J, Li Y, Adell G, Arbman G, Nodin B, Meng WJ, Zhang $\mathrm{H}$, Yu YY, Wang $\mathrm{C}$, et al: The prognostic factors and multiple biomarkers in young patients with colorectal cancer. Sci Rep 5: 10645, 2015.

54. Crosbie AB, Roche LM, Johnson LM, Pawlish KS, Paddock LE and Stroup AM: Trends in colorectal cancer incidence among younger adults-Disparities by age, sex, race, ethnicity, and subsite. Cancer Med 7: 4077-4086, 2018.

55. Ballester V, Rashtak S and Boardman L: Clinical and molecular features of young-onset colorectal cancer. World J Gastroenterol 22: 1736-1744, 2016.

56. Dozois EJ, Boardman LA, Suwanthanma W, Limburg PJ, Cima RR, Bakken JL, Vierkant RA, Aakre JA and Larson DW: Young-onset colorectal cancer in patients with no known genetic predisposition: Can we increase early recognition and improve outcome? Medicine (Baltimore) 87: 259-263, 2008.

57. O'Connell JB, Maggard MA, Liu JH, Etzioni DA, Livingston EH and Ko CY: Do young colon cancer patients have worse outcomes? World J Surg 28: 558-562, 2004.

58. Taggarshe D, Rehil N, Sharma S, Flynn JC and Damadi A: Colorectal cancer: Are the 'young' being overlooked? Am J Surg 205: 312-316, 2013.

59. Low EE, Demb J, Liu L, Earles A, Bustamante R, Williams CD Provenzale D, Kaltenbach T, Gawron AJ, Martinez ME and Gupta S: Risk factors for early-onset colorectal cancer. Gastroenterology 159: 492-501.e7, 2020.

60. Liu PH, Wu K, Ng K, Zauber AG, Nguyen LH, Song M, He X, Fuchs CS, Ogino S, Willett WC, et al: Association of obesity with risk of early-onset colorectal cancer among women. JAMA Oncol 5: 37-44, 2019.

61. Renehan AG, Tyson M, Egger M, Heller RF and Zwahlen M: Body-mass index and incidence of cancer: A systematic review and meta-analysis of prospective observational studies. Lancet 371: 569-578, 2008.

62. Dong Y, Zhou J, Zhu Y, Luo L, He T, Hu H, Liu H, Zhang Y, Luo D, Xu S, et al: Abdominal obesity and colorectal cancer risk: Systematic review and meta-analysis of prospective studies. Biosci Rep 37: BSR20170945, 2017.

63. Tejpar S and Van Cutsem E: Molecular and genetic defects in colorectal tumorigenesis. Best Pract Res Clin Gastroenterol 16: $171-185,2002$

64. Lengauer C, Kinzler KW and Vogelstein B: Genetic instability in colorectal cancers. Nature 386: 623-627, 1997.

65. Nojadeh JN, Behrouz Sharif S and Sakhinia E: Microsatellite instability in colorectal cancer. EXCLI J 17: 159-168, 2018

66. Vilar E and Gruber SB: Microsatellite instability in colorectal cancer-the stable evidence. Nat Rev Clin Oncol 7: 153-162, 2010.

67. Geiersbach KB and Samowitz WS: Microsatellite instability and colorectal cancer. Arch Pathol Lab Med 135: 1269-1277, 2011.

68. Lao VV and Grady WM: Epigenetics and colorectal cancer. Nat Rev Gastroenterol Hepatol 8: 686-700, 2011.

69. Kambara T, Simms LA, Whitehall VL, Spring KJ, Wynter CV, Walsh MD, Barker MA, Arnold S, McGivern A, Matsubara N, et al: BRAF mutation is associated with DNA methylation in serrated polyps and cancers of the colorectum Gut 53: 1137-1144, 2004.

70. Loeb LA, Loeb KR and Anderson JP: Multiple mutations and cancer. Proc Natl Acad Sci USA 100: 776-781, 2003.
71. Loeb LA: A mutator phenotype in cancer. Cancer Res 61 3230-3239, 2001

72. Prindle MJ, Fox EJ and Loeb LA: The mutator phenotype in cancer: Molecular mechanisms and targeting strategies. Curr Drug Targets 11: 1296-1303, 2010.

73. Lengauer C, Kinzler KW and Vogelstein B: Genetic instabilities in human cancers. Nature 396: 643-649, 1998.

74. Le Scouarnec S and Gribble SM: Characterising chromosome rearrangements: Recent technical advances in molecular cytogenetics. Heredity (Edinb) 108: 75-85, 2012.

75. Pino MS and Chung DC: The chromosomal instability pathway in colon cancer. Gastroenterology 138: 2059-2072, 2010.

76. Rowan A, Halford S, Gaasenbeek M, Kemp Z, Sieber O, Volikos E, Douglas E, Fiegler H, Carter N, Talbot I, et al: Refining molecular analysis in the pathways of colorectal carcinogenesis. Clin Gastroenterol Hepatol 3: 1115-1123, 2005.

77. Weber JC, Meyer N, Pencreach E, Schneider A, Guérin E, Neuville A, Stemmer C, Brigand C, Bachellier P, Rohr S, et al: Allelotyping analyses of synchronous primary and metastasis CIN colon cancers identified different subtypes. Int J Cancer 120: 524-532, 2007.

78. Cheng YW, Pincas H, Bacolod MD, Schemmann G, Giardina SF, Huang J, Barral S, Idrees K, Khan SA, Zeng Z, et al: CpG island methylator phenotype associates with low-degree chromosomal abnormalities in colorectal cancer. Clin Cancer Res 14: 6005-6013, 2008.

79. Grady WM: Epigenetic events in the colorectum and in colon cancer. Biochem Soc Trans 33: 684-688, 2005.

80. Shih IM, Zhou W, Goodman SN, Lengauer C, Kinzler KW and Vogelstein B: Evidence that genetic instability occurs at an early stage of colorectal tumorigenesis. Cancer Res 61: 818-822, 2001

81. Sieber OM, Heinimann K and Tomlinson IP: Genomic instability-the engine of tumorigenesis? Nat Rev Cancer 3: 701-708, 2003.

82. Thiagalingam S, Lengauer C, Leach FS, Schutte M, Hahn SA, Overhauser J, Willson JK, Markowitz S, Hamilton SR, Kern SE, et al: Evaluation of candidate tumor suppressor genes on chromosome 18 in colorectal cancers. Nat Genet 13: 343-346, 1996.

83. Powell SM, Zilz N, Beazer-Barclay Y, Bryan TM, Hamilton SR, Thibodeau SN, Vogelstein B and Kinzler KW: APC mutations occur early during colorectal tumorigenesis. Nature 359: 235-237, 1992.

84. Kinzler KW and Vogelstein B. Lessons from hereditary colorectal cancer. Cell 87: 159-170, 1996.

85. Su LK, Vogelstein B and Kinzler KW: Association of the APC tumor suppressor protein with catenins. Science 262: 1734-1737, 1993.

86. Bokoch GM and Der CJ: Emerging concepts in the Ras superfamily of GTP-binding proteins. FASEB J 7: 750-759, 1993.

87. Arber N, Shapira I, Ratan J, Stern B, Hibshoosh H, Moshkowitz M, Gammon M, Fabian I and Halpern Z: Activation of c-K-ras mutations in human gastrointestinal tumors. Gastroenterology 118: 1045-1050, 2000

88. Bos JL, Fearon ER, Hamilton SR, Verlaan-de Vries M, van Boom JH, van der Eb AJ and Vogelstein B: Prevalence of ras gene mutations in human colorectal cancers. Nature 327 293-297, 1987.

89. Nguyen HT and Duong HQ: The molecular characteristics of colorectal cancer: Implications for diagnosis and therapy. Oncol Lett 16: 9-18, 2018

90. Tanaka T,Watanabe T,Kazama Y,Tanaka J,Kanazawa T,KazamaS and Nagawa H: Chromosome 18q deletion and Smad4 protein inactivation correlate with liver metastasis: A study matched for T- and N-classification. Br J Cancer 95: 1562-1567, 2006.

91. Zauber P, Sabbath-Solitare M, Marotta SP and Bishop T: Loss of heterozygosity for chromosome $18 \mathrm{q}$ and microsatellite instability are highly consistent across the region of the DCC and SMAD4 genes in colorectal carcinomas and adenomas. J Appl Res 8: 14 , 2008.

92. Kirley SD, D'Apuzzo M, Lauwers GY, Graeme-Cook F, Chung DC and Zukerberg LR: The Cables gene on chromosome $18 \mathrm{Q}$ regulates colon cancer progression in vivo. Cancer Biol Ther 4:861-863, 2005

93. Jung B, Staudacher JJ and Beauchamp D: Transforming growth factor $\beta$ superfamily signaling in development of colorectal cancer. Gastroenterology 152: 36-52, 2017.

94. Muzny DM, Bainbridge M, Chang K, Dinh HH, Drummond JA, Fowler G, Kovar CL, Lewis LR, Morgan MB, Morgan I, et al: Comprehensive molecular characterization of human colon and rectal cancer. Nature 487: 330-337, 2012. 
95. Mehlen P and Fearon ER: Role of the dependence receptor DCC in colorectal cancer pathogenesis. J Clin Oncol 22: 3420-3428, 2004.

96. Hedrick L, Cho KR and Vogelstein B: Cell adhesion molecules as tumor suppressors. Trends Cell Biol 3: 36-39, 1993.

97. Martínez-López E, Abad A, Font A, Monzó M, Ojanguren I, Pifarré A, Sánchez JJ, Martín C and Rosell R: Allelic loss on chromosome $18 \mathrm{q}$ as a prognostic marker in stage II colorectal cancer. Gastroenterology 114: 1180-1187, 1998.

98. Saha MN, Qiu L and Chang H: Targeting p53 by small molecules in hematological malignancies. J Hematol Oncol 6: 23, 2013.

99. Li H, Zhang J, Tong JHM, Chan AWH, Yu J, Kang W and To KF: Targeting the oncogenic p53 mutants in colorectal cancer and other solid tumors. Int J Mol Sci 20: 5999, 2019.

100. López I, P Oliveira L, Tucci P, Alvarez-Valín F, A Coudry R and Marín M: Different mutation profiles associated to P53 accumulation in colorectal cancer. Gene 499: 81-87, 2012.

101. Russo A, Bazan V, Iacopetta B, Kerr D, Soussi T and Gebbia N; TP53-CRC Collaborative Study Group: The TP53 colorectal cancer international collaborative study on the prognostic and predictive significance of p53 mutation: Influence of tumor site, type of mutation, and adjuvant treatment. J Clin Oncol 23 7518-7528, 2005.

102. Sigal A and Rotter V: Oncogenic mutations of the p53 tumor suppressor: The demons of the guardian of the genome. Cancer Res 60: 6788-6793, 2000.

103. Teodoro JG, Evans SK and Green MR: Inhibition of tumor angiogenesis by p53: A new role for the guardian of the genome. J Mol Med (Berl) 85: 1175-1186, 2007.

104. Levine AJ: p53, the cellular gatekeeper for growth and division Cell 88: 323-331, 1997

105. Howe JR and Guillem JG: The genetics of colorectal cancer Surg Clin North Am 77: 175-195, 1997.

106. Boland CR and Goel A: Microsatellite instability in colorectal cancer. Gastroenterology 138: 2073-2087.e3, 2010.

107. Boland CR: The molecular biology of gastrointestinal cancer: Implications for diagnosis and therapy. Gastrointest Endosc Clin N Am 18: 401-413, vii, 2008.

108. Boland CR, Thibodeau SN, Hamilton SR, Sidransky D, Eshleman JR, Burt RW, Meltzer SJ, Rodriguez-Bigas MA, Fodde R, Ranzani GN and Srivastava S: A national cancer institute workshop on microsatellite instability for cancer detection and familial predisposition: Development of international criteria for the determination of microsatellite instability in colorectal cancer. Cancer Res 58: 5248-5257, 1998.

109. Findeisen P, Kloor M, Merx S, Sutter C, Woerner SM, Dostmann N, Benner A, Dondog B, Pawlita M, Dippold W, et al: T25 repeat in the $3^{\prime}$ untranslated region of the CASP2 gene: a sensitive and specific marker for microsatellite instability in colorectal cancer. Cancer Res 65: 8072-8078, 2005.

110. Lynch HT, Lynch PM, Lanspa SJ, Snyder CL, Lynch JF and Boland CR: Review of the Lynch syndrome: History, molecular genetics, screening, differential diagnosis, and medicolegal ramifications. Clin Genet 76: 1-18, 2009.

111. van Rijnsoever M, Grieu F, Elsaleh H, Joseph D and Iacopetta B: Characterisation of colorectal cancers showing hypermethylation at multiple CpG islands. Gut 51: 797-802, 2002.

112. Toyota M, Ahuja N, Ohe-Toyota M, Herman JG, Baylin SB and Issa JPJ: CpG island methylator phenotype in colorectal cancer. Proc Natl Acad Sci USA 96: 8681-8686, 1999.

113. Jass JR: Serrated adenoma of the colorectum and the DNA-methylator phenotype. Nat Clin Pract Oncol 2: 398-405, 2005 .

114. Samowitz WS, Albertsen H, Herrick J, Levin TR, Sweeney C, Murtaugh MA, Wolff RK and Slattery ML: Evaluation of a large, population-based sample supports a $\mathrm{CpG}$ island methylator phenotype in colon cancer. Gastroenterology 129: 837-845, 2005.

115. Hawkins N, Norrie M, Cheong K, Mokany E, Ku SL, Meagher A, O'Connor T and Ward R: CpG island methylation in sporadic colorectal cancers and its relationship to microsatellite instability. Gastroenterology 122: 1376-1387, 2002

116. Chan AOO, Issa JPJ, Morris JS, Hamilton SR and Rashid A: Concordant $\mathrm{CpG}$ island methylation in hyperplastic polyposis Am J Pathol 160: 529-536, 2002.

117. Wynter CVA, Walsh MD, Higuchi T, Leggett BA, Young J and Jass JR: Methylation patterns define two types of hyperplastic polyp associated with colorectal cancer. Gut 53: 573-580, 2004.

118. Minoo P, Baker K, Goswami R, Chong G, Foulkes WD Ruszkiewicz AR, Barker M, Buchanan D, Young J and Jass JR: Extensive DNA methylation in normal colorectal mucosa in hyperplastic polyposis. Gut 55: 1467-1474, 2006.
119. Shima K, Morikawa T, Yamauchi M, Kuchiba A, Imamura Y, Liao X, Meyerhardt JA, Fuchs CS and Ogino S: TGFBR2 and BAX mononucleotide tract mutations, microsatellite instability, and prognosis in 1072 colorectal cancers. PLoS One 6: e25062, 2011.

120. Edelstein DL, Axilbund JE, Hylind LM, Romans K, Griffin CA, Cruz-Correa M and Giardiello FM: Serrated polyposis: Rapid and relentless development of colorectal neoplasia. Gut 62: 404-408, 2013.

121. Bettington M, Walker N, Rosty C, Brown I, Clouston A McKeone D, Pearson SA, Leggett B and Whitehall V: Clinicopathological and molecular features of sessile serrated adenomas with dysplasia or carcinoma. Gut 66: 97-106, 2017.

122. Johnson CM, Wei C, Ensor JE, Smolenski DJ, Amos CI, Levin B and Berry DA: Meta-analyses of colorectal cancer risk factors. Cancer Causes Control 24: 1207-1222, 2013.

123. Zisman AL, Nickolov A, Brand RE, Gorchow A and Roy HK: Associations between the age at diagnosis and location of colorectal cancer and the use of alcohol and tobacco: Implications for screening. Arch Intern Med 166: 629-634, 2006.

124. Botteri E, Iodice S, Bagnardi V, Raimondi S, Lowenfels AB and Maisonneuve P: Smoking and colorectal cancer: A meta-analysis. JAMA 300: 2765-2778, 2008.

125. Pande M, Lynch PM, Hopper JL, Jenkins MA, Gallinger S, Haile RW, LeMarchand L, Lindor NM, Campbell PT, Newcomb PA, et al: Smoking and colorectal cancer in Lynch syndrome: Results from the colon cancer family registry and the University of Texas M.D. Anderson cancer center. Clin Cancer Res 16: 1331-1339, 2010

126. Figueiredo JC, Crockett SD, Snover DC, Morris CB, McKeown-Eyssen G, Sandler RS, Ahnen DJ, Robertson DJ, Burke CA, Bresalier RS, et al: Smoking-associated risks of conventional adenomas and serrated polyps in the colorectum. Cancer Causes Control 26: 377-386, 2015.

127. Limsui D, Vierkant RA, Tillmans LS, Wang AH, Weisenberger DJ, Laird PW, Lynch CF, Anderson KE, French AJ, Haile RW, et al: Cigarette smoking and colorectal cancer risk by molecularly defined subtypes. J Natl Cancer Inst 102: 1012-1022, 2010.

128. Hannan LM, Jacobs EJ and Thun MJ: The association between cigarette smoking and risk of colorectal cancer in a large prospective cohort from the United States. Cancer Epidemiol Biomarkers Prev 18: 3362-3367, 2009.

129. Ordóñez-Mena JM, Walter V, Schöttker B, Jenab M, O'Doherty MG, Kee F, Bueno-de-Mesquita B, Peeters PHM, Stricker BH, Ruiter R, et al: Impact of prediagnostic smoking and smoking cessation on colorectal cancer prognosis: A meta-analysis of individual patient data from cohorts within the CHANCES consortium. Ann Oncol 29: 472-483, 2018.

130. Pöschl G and Seitz HK: Alcohol and cancer. Alcohol Alcohol 39: $155-165,2004$

131. Fedirko V, Tramacere I, Bagnardi V, Rota M, Scotti L, Islami F, Negri E, Straif K, Romieu I,La Vecchia C, et al: Alcohol drinking and colorectal cancer risk: An overall and dose-response meta-analysis of published studies. Ann Oncol 22: 1958-1972, 2011.

132. Choi YJ, Myung SK and Lee JH: Light alcohol drinking and risk of cancer: A meta-analysis of cohort studies. Cancer Res Treat 50: 474-487, 2018.

133. Cho E, Smith-Warner SA, Ritz J, van den Brandt PA, Colditz GA, Folsom AR, Freudenheim JL, Giovannucci E, Goldbohm RA, Graham S, et al: Alcohol intake and colorectal cancer: A pooled analysis of 8 cohort studies. Ann Intern Med 140: 603-613, 2004.

134. Praud D, Rota M, Rehm J, Shield K, Zatoński W, Hashibe M, La Vecchia C and Boffetta P: Cancer incidence and mortality attributable to alcohol consumption. Int J Cancer 138: 1380-1387, 2016.

135. Nelson DE, Jarman DW, Rehm J, Greenfield TK, Rey G, Kerr WC, Miller P, Shield KD, Ye Y and Naimi TS: Alcohol-attributable cancer deaths and years of potential life lost in the United States. Am J Public Health 103: 641-648, 2013.

136. Butler LM, Sinha R, Millikan RC, Martin CF, Newman B, Gammon MD, Ammerman AS and Sandler RS: Heterocyclic amines, meat intake, and association with colon cancer in a population-based study. Am J Epidemiol 157: 434-445, 2003.

137. Kampman E, Slattery ML, Bigler J, Leppert M, Samowitz W, Caan BJ and Potter JD: Meat consumption, genetic susceptibility, and colon cancer risk: A United States multicenter case-control study. Cancer Epidemiol Biomarkers Prev 8: 15-24, 1999. 
138. Santarelli RL, Pierre F and Corpet DE: Processed meat and colorectal cancer: A review of epidemiologic and experimental evidence. Nutr Cancer 60: 131-144, 2008.

139. Kabat GC, Miller AB, Jain M and Rohan TE: A cohort study of dietary iron and heme iron intake and risk of colorectal cancer in women. Br J Cancer 97: 118-122, 2007.

140. Sinha R: An epidemiologic approach to studying heterocyclic amines. Mutat Res 506-507: 197-204, 2002.

141. Pietinen P, Malila N, Virtanen M, Hartman TJ, Tangrea JA, Albanes D and Virtamo J: Diet and risk of colorectal cancer in a cohort of Finnish men. Cancer Causes Control 10: 387-396, 1999.

142. Terry P, Giovannucci E, Michels KB, Bergkvist L, Hansen H, Holmberg L and Wolk A: Fruit, vegetables, dietary fiber, and risk of colorectal cancer. J Natl Cancer Inst 93: 525-533, 2001.

143. Bardou M, Barkun AN and Martel M: Obesity and colorectal cancer. Gut 62: 933-947, 2013.

144. Kelly DM and Jones TH: Testosterone and obesity. Obes Rev 16 : 581-606, 2015.

145. Matsuo K, Mizoue T, Tanaka K, Tsuji I, Sugawara Y, Sasazuki S, Nagata C, Tamakoshi A, Wakai K, Inoue M, et al: Association between body mass index and the colorectal cancer risk in Japan: Pooled analysis of population-based cohort studies in Japan. Ann Oncol 23: 479-490, 2012.

146. Goh LY and Goh KL: Obesity: An epidemiological perspective from Asia and its relationship to gastrointestinal and liver cancers. J Gastroenterol Hepatol 28 (Suppl 4): S54-S58, 2013.

147. World Cancer Research Fund: Continuous update project report. Food, nutrition, physical activity, and the prevention of colorectal cancer. WCRF/AICR, 2011.

148. Song M, Hu FB, Spiegelman D, Chan AT, Wu K, Ogino S, Fuchs CS, Willett WC and Giovannucci EL: Long-term status and change of body fat distribution, and risk of colorectal cancer: A prospective cohort study. Int J Epidemiol 45: 871-883, 2016.

149. Moore LL, Bradlee ML, Singer MR, Splansky GL, Proctor MH, Ellison RC and Kreger BE: BMI and waist circumference as predictors of lifetime colon cancer risk in Framingham study adults. Int J Obes Relat Metab Disord 28: 559-567, 2004.

150. Samaras K, Botelho NK, Chisholm DJ and Lord RV: Subcutaneous and visceral adipose tissue gene expression of serum adipokines that predict type 2 diabetes. Obesity (Silver Spring) 18: 884-889, 2010.

151. Lim U, Ernst T, Buchthal SD, Latch M, Albright CL, Wilkens LR, Kolonel LN, Murphy SP, Chang L, Novotny R and Le Marchand L: Asian women have greater abdominal and visceral adiposity than Caucasian women with similar body mass index. Nutr Diabetes 1: e6, 2011.

152. Ma Y, Yang Y, Wang F, Zhang P, Shi C, Zou Y and Qin H: Obesity and risk of colorectal cancer: A systematic review of prospective studies. PLoS One 8: e53916, 2013.

153. Lee YJ, Myung SK, Cho B, Park BJ, Park JH, Ju W, Park MS and Choi JH: Adiposity and the risk of colorectal adenomatous polyps: A meta-analysis. Cancer Causes Control 22: 1021-1035, 2011.

154. Guraya SY: Association of type 2 diabetes mellitus and the risk of colorectal cancer: A meta-analysis and systematic review. World J Gastroenterol 21: 6026-6031, 2015.

155. Kahn SE, Hull RL and Utzschneider KM: Mechanisms linking obesity to insulin resistance and type 2 diabetes. Nature 444 : 840-846, 2006.

156. Moller DE and Flier JS: Insulin resistance-mechanisms, syndromes, and implications. N Engl J Med 325: 938-948, 1991.

157. Pollak M: Insulin and insulin-like growth factor signalling in neoplasia. Nat Rev Cancer 8: 915-928, 2008.

158. Calle EE and Kaaks R: Overweight, obesity and cancer: Epidemiological evidence and proposed mechanisms. Nat Rev Cancer 4: 579-591, 2004.

159. Murphy N, Strickler HD, Stanczyk FZ, Xue X, Wassertheil-Smoller S, Rohan TE, Ho GY, Anderson GL, Potter JD and Gunter MJ: A prospective evaluation of endogenous sex hormone levels and colorectal cancer risk in postmenopausal women. J Natl Cancer Inst 107: djv210, 2015.

160. Hetemäki N, Savolainen-Peltonen H, Tikkanen MJ, Wang F, Paatela H, Hämäläinen E, Turpeinen U, Haanpää M, Vihma V and Mikkola TS: Estrogen metabolism in abdominal subcutaneous and visceral adipose tissue in postmenopausal women. J Clin Endocrinol Metab 102: 4588-4595, 2017.

161. Burkitt DP: Epidemiology of cancer of the colon and rectum. Cancer 28: 3-13, 1971.
162. Aune D, Chan DS, Lau R, Vieira R, Greenwood DC, Kampman E and Norat T: Dietary fibre, whole grains, and risk of colorectal cancer: Systematic review and dose-response meta-analysis of prospective studies. BMJ 343: d6617, 2011.

163. World Cancer Research Fund: Diet, nutrition, physical activity and cancer: A global perspective: A summary of the third expert report. World Cancer Research Fund International, 2018.

164. Rezende LFM, Sá TH, Markozannes G, Rey-López JP, Lee IM, Tsilidis KK, Ioannidis JPA and Eluf-Neto J: Physical activity and cancer: An umbrella review of the literature including 22 major anatomical sites and 770000 cancer cases. Br J Sports Med 52: 826-833, 2018

165. Morris JS, Bradbury KE, Cross AJ, Gunter MJ and Murphy N: Physical activity, sedentary behaviour and colorectal cancer risk in the UK Biobank. Br J Cancer 118: 920-929, 2018.

166. Keum N, Bao Y, Smith-Warner SA, Orav J, Wu K, Fuchs CS and Giovannucci EL: Association of physical activity by type and intensity with digestive system cancer risk. JAMA Oncol 2: 1146-1153, 2016.

167. Ma P, Yao Y, Sun W, Dai S and Zhou C: Daily sedentary time and its association with risk for colorectal cancer in adults: A dose-response meta-analysis of prospective cohort studies. Medicine (Baltimore) 96: e7049, 2017.

168. Lynch BM: Sedentary behavior and cancer: A systematic review of the literature and proposed biological mechanisms. Cancer Epidemiol Biomarkers Prev 19: 2691-2709, 2010.

169. Howard RA, Freedman DM, Park Y, Hollenbeck A, Schatzkin A and Leitzmann MF: Physical activity, sedentary behavior, and the risk of colon and rectal cancer in the NIH-AARP diet and health study. Cancer Causes Control 19: 939-953, 2008.

170. Jeong WJ, Ro EJ and Choi KY: Interaction between Wnt/ $\beta$-catenin and RAS-ERK pathways and an anti-cancer strategy via degradations of $\beta$-catenin and RAS by targeting the Wnt/ $\beta$-catenin pathway. NPJ Precis Oncol 2: 5, 2018.

171. Novellasdemunt L, Antas P and Li VS: Targeting Wnt signalling in colorectal cancer. A review in the theme: Cell Signalling: Proteins, pathways and mechanisms. Am J Physiol Cell Physiol 309: C511-C521, 2015.

172. Farooqi AA, de la Roche M, Djamgoz MBA and Siddik ZH: Overview of the oncogenic signalling pathways in colorectal cancer: Mechanistic insights. Semin Cancer Biol 58: 65-79, 2019.

173. Koveitypour Z, Panahi F, Vakilian M, Peymani M, Seyed Forootan F, Nasr Esfahani MH and Ghaedi K: Signaling pathways involved in colorectal cancer progression. Cell Biosci 9: 97, 2019.

174. Pandurangan AK, Divya T, Kumar K, Dineshbabu V, Velavan B and Sudhandiran G: Colorectal carcinogenesis: Insights into the cell death and signal transduction pathways: A review. World $\mathbf{J}$ Gastrointest Oncol 10: 244-259, 2018.

175. Tiwari A, Saraf S, Verma A, Panda PK and Jain SK: Novel targeting approaches and signaling pathways of colorectal cancer: An insight. World J Gastroenterol 24: 4428-4435, 2018.

176. Folkman J: Tumor angiogenesis: Therapeutic implications. $\mathrm{N}$ Engl J Med 285: 1182-1186, 1971.

177. Saharinen P, Eklund L, Pulkki K, Bono P and Alitalo K: VEGF and angiopoietin signaling in tumor angiogenesis and metastasis. Trends Mol Med 17: 347-362, 2011.

178. Goel HL and Mercurio AM: VEGF targets the tumor cell. Nat Rev Cancer 13: 871-882, 2013.

179. Ferrara N, Gerber HP and LeCouter J: The biology of VEGF and its receptors. Nat Med 9: 669-676, 2003.

180. Lee YJ, Karl DL, Maduekwe UN, Rothrock C, Ryeom S, D'Amore PA and Yoon SS: Differential effects of VEGFR-1 and VEGFR-2 inhibition on tumor metastases based on host organ environment. Cancer Res 70: 8357-8367, 2010.

181. Vaahtomeri K, Karaman S, Mäkinen T and Alitalo K: Lymphangiogenesis guidance by paracrine and pericellular factors. Genes Dev 31: 1615-1634, 2017.

182. Olsson AK, Dimberg A, Kreuger J and Claesson-Welsh L: VEGF receptor signalling-in control of vascular function. Nat Rev Mol Cell Biol 7: 359-371, 2006.

183. Takahashi $\mathrm{H}$ and Shibuya M: The vascular endothelial growth factor (VEGF)/VEGF receptor system and its role under physiological and pathological conditions. Clin Sci (Lond) 109: 227-241, 2005

184. Koch S and Claesson-Welsh L: Signal transduction by vascular endothelial growth factor receptors. Cold Spring Harb Perspect Med 2: a006502, 2012. 
185. Garnier L, Gkountidi AO and Hugues S: Tumor-associated lymphatic vessel features and immunomodulatory functions. Front Immunol 10: 720, 2019.

186. Secker GA and Harvey NL: VEGFR signaling during lymphatic vascular development: From progenitor cells to functional vessels. Dev Dyn 244: 323-331, 2015.

187. Cébe-Suarez S, Zehnder-Fjällman A and Ballmer-Hofer K: The role of VEGF receptors in angiogenesis; complex partnerships. Cell Mol Life Sci 63: 601-615, 2006.

188. Lopez A, Harada K, Vasilakopoulou M, Shanbhag N and Ajani JA: Targeting angiogenesis in colorectal carcinoma. Drugs 79: 63-74, 2019.

189. Seeber A, Gunsilius E, Gastl G and Pircher A: Anti-angiogenics: Their value in colorectal cancer therapy. Oncol Res Treat 41: 188-193, 2018

190. Guba M, Seeliger H, Kleespies A, Jauch KW and Bruns C: Vascular endothelial growth factor in colorectal cancer. Int J Colorectal Dis 19: 510-517, 2004.

191. Jain RK: Antiangiogenesis strategies revisited: From starving tumors to alleviating hypoxia. Cancer Cell 26: 605-622, 2014.

192. Amelio I and Melino G: The p53 family and the hypoxia-inducible factors (HIFs): Determinants of cancer progression. Trends Biochem Sci 40: 425-434, 2015

193. Tarnawski AS, Ahluwalia A and Jones MK: Angiogenesis in gastric mucosa: An important component of gastric erosion and ulcer healing and its impairment in aging. J Gastroenterol Hepatol 29 (Suppl 4): S112-S23, 2014.

194. Wang Q, Yang S, Wang K and Sun SY: MET inhibitors for targeted therapy of EGFR TKI-resistant lung cancer. J Hematol Oncol 12: 63, 2019

195. Cheng F and Guo D: MET in glioma: Signaling pathways and targeted therapies. J Exp Clin Cancer Res 38: 270, 2019.

196. Demkova L and Kucerova L: Role of the HGF/c-MET tyrosine kinase inhibitors in metastasic melanoma. Mol Cancer 17: 26 , 2018

197. Lam BQ, Dai L and Qin Z: The role of HGF/c-MET signaling pathway in lymphoma. J Hematol Oncol 9: 135, 2016.

198. Bradley CA, Salto-Tellez M, Laurent-Puig P, Bardelli A Rolfo C, Tabernero J, Khawaja HA, Lawler M, Johnston PG and Van Schaeybroeck S; MErCuRIC consortium: Targeting c-MET in gastrointestinal tumors: Rationale, opportunities and challenges. Nat Rev Clin Oncol 14: 562-576, 2017.

199. Xing F, Liu Y, Sharma S, Wu K, Chan MD, Lo HW, Carpenter RL, Metheny-Barlow LJ, Zhou X, Qasem SA, et al: Activation of the c-Met pathway mobilizes an inflammatory network in the brain microenvironment to promote brain metastasis of breast cancer. Cancer Res 76: 4970-4980, 2016

200. Ozawa Y, Nakamura Y, Fujishima F, Felizola SJ, Takeda K, Okamoto H, Ito K, Ishida H, Konno T, Kamei T, et al: c-Met in esophageal squamous cell carcinoma: An independent prognostic factor and potential therapeutic target. BMC Cancer 15: 451,2015

201. Anestis A, Zoi I and Karamouzis MV: Current advances of targeting $\mathrm{HGF} / \mathrm{c}-\mathrm{Met}$ pathway in gastric cancer. Ann Trans Med 6: 247, 2018 .

202.Safaie Qamsari E, Safaei Ghaderi S, Zarei B, Dorostkar R, Bagheri S, Jadidi-Niaragh F, Somi MH and Yousefi M: The c-Met receptor: Implication for targeted therapies in colorectal cancer. Tumor Biol 39: 1010428317699118, 2017.

203. Otte JM, Schmitz F, Kiehne K, Stechele HU, Banasiewicz T, Krokowicz P, Nakamura T, Fölsch UR and Herzig K: Functional expression of $\mathrm{HGF}$ and its receptor in human colorectal cancer. Digestion 61: 237-246, 2000

204. Matsumoto K, Umitsu M, De Silva DM, Roy A and Bottaro DP. Hepatocyte growth factor/MET in cancer progression and biomarker discovery. Cancer Sci 108: 296-307, 2017.

205. Bahrami A, Shahidsales S, Khazaei M, Ghayour-Mobarhan M, Maftouh M, Hassanian SM and Avan A: C-Met as a potentia target for the treatment of gastrointestinal cancer: Current status and future perspectives. J Cell Physiol 232: 2657-2673, 2017.

206. Mo HN and Liu P: Targeting MET in cancer therapy. Chronic Dis Transl Med 3: 148-153, 2017.

207. Bouattour M, Raymond E, Qin S, Cheng AL, Stammberger U, Locatelli $\mathrm{G}$ and Faivre S: Recent developments of c-Met as a therapeutic target in hepatocellular carcinoma. Hepatology 67: 1132-1149, 2018.

208. Drilon A, Cappuzzo F, Ou SI and Camidge DR: Targeting MET in lung cancer: Will expectations finally be MET? J Thorac Oncol 12: 15-26, 2017

209. Blumenschein GR Jr, Mills GB and Gonzalez-Angulo AM: Targeting the hepatocyte growth factor-cMET axis in cancer therapy. J Clin Oncol 30: 3287-3296, 2012.
210. Cabanillas ME, de Souza JA, Geyer S, Wirth LJ, Menefee ME, Liu SV, Shah K, Wright J and Shah MH: Cabozantinib as salvage therapy for patients with tyrosine kinase inhibitor-refractory differentiated thyroid cancer: Results of a multicenter phase II international thyroid oncology group trial. J Clin Oncol 35: 3315-3321, 2017

211. Cancer Genome Atlas Research Network; Linehan WM, Spellman PT, Ricketts CJ, Creighton CJ, Fei SS, Davis C, Wheeler DA, Murray BA, Schmidt L, et al: Comprehensive molecular characterization of papillary renal-cell carcinoma. $\mathrm{N}$ Engl J Med 374: 135-145, 2016.

212. Catenacci DVT, Tebbutt NC, Davidenko I, Murad AM, Al-Batran SE, IlsonDH,Tjulandin S, Gotovkin E, KaraszewskaB, Bondarenko I, et al: Rilotumumab plus epirubicin, cisplatin, and capecitabine as first-line therapy in advanced MET-positive gastric or gastro-oesophageal junction cancer (RILOMET-1): A randomised, double-blind, placebo-controlled, phase 3 trial. Lancet Oncol 18: 1467-1482, 2017.

213. Sartore-Bianchi A, Loupakis F, Argilés G and Prager GW: Challenging chemoresistant metastatic colorectal cancer: Therapeutic strategies from the clinic and from the laboratory. Ann Oncol 27: 1456-1466, 2016.

214. Gao H, Guan M, Sun Z and Bai C: High c-Met expression is a negative prognostic marker for colorectal cancer: A meta-analysis. Tumor Biol 36: 515-520, 2015.

215. Luo HY and Xu RH: Predictive and prognostic biomarkers with therapeutic targets in advanced colorectal cancer. World J Gastroenterol 20: 3858-3874, 2014.

216. Baldus SE, Kort EJ, Schirmacher P, Dienes HP and Resau JH: Quantification of MET and hepatocyte growth factor/scatter factor expression in colorectal adenomas, carcinomas and non-neoplastic epithelia by quantitative laser scanning microscopy. Int J Oncol 31: 199-204, 2007.

217. Kentsis A, Reed C, Rice KL, Sanda T, Rodig SJ, Tholouli E, Christie A, Valk PJ, Delwel R, Ngo V, et al: Autocrine activation of the MET receptor tyrosine kinase in acute myeloid leukemia. Nat Med 18: 1118-1122, 2012.

218. Stein U, Walther W, Arlt F, Schwabe H, Smith J, Fichtner I, Birchmeier W and Schlag PM: MACC1, a newly identified key regulator of HGF-MET signaling, predicts colon cancer metastasis. Nat Med 15: 59-67, 2009.

219. Parseghian CM, Napolitano S, Loree JM and Kopetz S: Mechanisms of innate and acquired resistance to anti-EGFR therapy: A review of current knowledge with a focus on rechallenge therapies. Clin Cancer Res 25: 6899-6908, 2019.

220. Boccaccio C, Luraghi P and Comoglio PM: MET-mediated resistance to EGFR inhibitors: An old liaison rooted in colorectal cancer stem cells. Cancer Res 74: 3647-3651, 2014.

221. Van Emburgh BO, Sartore-Bianchi A, Di Nicolantonio F, Siena S and Bardelli A: Acquired resistance to EGFR-targeted therapies in colorectal cancer. Mol Oncol 8: 1084-1094, 2014.

222. Viticchiè G and Muller PAJ: c-Met and other cell surface molecules: Interaction, activation and functional consequences. Biomedicines 3: 46-70, 2015

223. Sharpe AH and Freeman GJ: The B7-CD28 superfamily. Nat Rev Immunol 2: 116-126, 2002

224. Jelinek T, Mihalyova J, Kascak M, Duras J and Hajek R: PD-1/PD-L1 inhibitors in haematological malignancies: Update 2017. Immunology 152: 357-371, 2017.

225. Chen L and Han X: Anti-PD-1/PD-L1 therapy of human cancer: Past, present, and future. J Clin Invest 125: 3384-3391, 2015.

226. Markman JL and Shiao SL: Impact of the immune system and immunotherapy in colorectal cancer. J Gastrointest Oncol 6: 208-223, 2015

227. Xie YH, Chen YX and Fang JY: Comprehensive review of targeted therapy for colorectal cancer. Signal Transduct Target Ther 5: 22, 2020.

228. Pauken KE and Wherry EJ: Overcoming T cell exhaustion in infection and cancer. Trends Immunol 36: 265-276, 2015.

229. Wang HB, Yao H, Li CS, Liang LX, Zhang Y, Chen YX, Fang JY and $\mathrm{Xu}$ J: Rise of PD-L1 expression during metastasis of colorectal cancer: Implications for immunotherapy. J Dig Dis 18: 574-581, 2017.

230.Fujimoto H, Saito Y, Ohuchida K, Kawakami E, Fujiki S, Watanabe T, Ono R, Kaneko A, Takagi S, Najima Y, et al: Deregulated mucosal immune surveillance through gut-associated regulatory $\mathrm{T}$ cells and PD-1 $1^{+} \mathrm{T}$ cells in human colorectal cancer. J Immunol 200: 3291-3303, 2018.

231. Vinson KE, George DC, Fender AW, Bertrand FE and Sigounas G: The Notch pathway in colorectal cancer. Int J Cancer 138: 1835-1842, 2016. 
232.Zhi X, Tao J, Zhang L, Tao R, Ma L and Qin J: Silencing speckle-type POZ protein by promoter hypermethylation decreases cell apoptosis through upregulating hedgehog signaling pathway in colorectal cancer. Cell Death Dis 7, e2569, 2016.

233. Wu C, Zhu X, Liu W, Ruan T and Tao K: Hedgehog signalling pathway in colorectal cancer: Function, mechanism, and therapy. Onco Targets Ther 10: 3249-3259, 2017.

234. Han Y: Analysis of the role of the Hippo pathway in cancer. J Transl Med 17: 116, 2019.

235.Zhang YE: Non-Smad pathways in TGF- $\beta$ signaling. Cell Res 19: 128-139, 2009.

236. Cheruku HR, Mohamedali A, Cantor DI, Tan SH, Nice EC and Baker MS: Transforming growth factor- $\beta$, MAPK and Wnt signaling interaction in colorectal cancer. EuPA Open Proteomics 8, 104-115, 2015.

237. Luo K: Signaling cross talk between TGF- $\beta /$ Smad and other signaling pathways. Cold Spring Harb Perspect Biol 9: a022137, 2017.

238. Lee Y, Kim NH, Cho ES, Yang JH, Cha YH, Kang HE, Yun JS, Cho SB, Lee SH, Paclikova P, et al: Dishevelled has a YAP nuclear export function in a tumor suppressor context-dependent manner. Nat Commun 9, 2301, 2018.

239. Jing L, Li J, Zhang C, Shang Y and Lin J: YAP-mediated crosstalk between the Wnt and Hippo signaling pathways (Review). Mol Med Rep 22, 4101-4106, 2020.

240.Pietrobono S, Gagliardi S and Stecca B: Non-canonical hedgehog signalling pathway in cancer: Activation of GLI transcription factors beyond smoothened. Front Genet 10: 556, 2019.

241. Regan JL, Schumacher D, Staudte S, Steffen A, Haybaeck J, Keilholz U, Schweiger C, Golob-Schwarzl N, Mumberg D, Henderson D, et al: Non-canonical hedgehog signaling is a positive regulator of the WNT pathway and is required for the survival of colon cancer stem cells. Cell Rep 21: 2813-2828, 2017.

242.Heidelberger C, Chaudhuri NK, Danneberg P, Mooren D, Griesbach L, Duschinsky R, Schnitzer RJ, Pleven E and Scheiner J: Fluorinated pyrimidines, a new class of tumor-inhibitory compounds. Nature 179: 663-666, 1957.

243. Piawah S and Venook AP: Targeted therapy for colorectal cancer metastases: A review of current methods of molecularly targeted therapy and the use of tumor biomarkers in the treatment of metastatic colorectal cancer. Cancer 125: 4139-4147, 2019.

244.Piedbois P, Buyse M, Rustum Y, Machover D, Erlichman C, Carlson RW, Valone F, Labianca R, Doroshow JH and Petrelli N: Modulation of fluorouracil by leucovorin in patients with advanced colorectal cancer: Evidence in terms of response rate by the advanced colorectal cancer meta-analysis project. J Clin Oncol 10: 896-903, 1992.

245. de Gramont A, Figer A, Seymour M, Homerin M, Hmissi A, Cassidy J, Boni C, Cortes-Funes H, Cervantes A, Freyer G, et al: Leucovorin and fluorouracil with or without oxaliplatin as first-line treatment in advanced colorectal cancer. J Clin Oncol 18: 2938-2947, 2000.

246. Douillard JY, Cunningham D, Roth AD, Navarro M, James RD, Karasek P, Jandik P, Iveson T, Carmichael J, Alak1 M, et al: Irinotecan combined with fluorouracil compared with fluorouracil alone as first-line treatment for metastatic colorectal cancer: A multicentre randomised trial. Lancet 355: 1041-1047, 2000.

247. Tournigand C, André T, Achille E, Lledo G, Flesh M, Mery-Mignard D, Quinaux E, Couteau C, Buyse M, Ganem G, et al: FOLFIRI followed by FOLFOX6 or the reverse sequence in advanced colorectal cancer: A randomized GERCOR study. J Clin Oncol 22: 229-237, 2004.

248. Colucci G, Gebbia V, Paoletti G, Giuliani F, Caruso M, Gebbia N, Cartenì G, Agostara B, Pezzella G, Manzione L, et al: Phase III randomized trial of FOLFIRI versus FOLFOX4 in the treatment of advanced colorectal cancer: A multicenter study of the gruppo oncologico Dell'Italia meridionale. J Clin Oncol 23: 4866-4875, 2005

249. Cassidy J, Clarke S, Díaz-Rubio E, Scheithauer W, Figer A, Wong R, Koski S, Lichinitser M, Yang TS, Rivera F, et al: Randomized phase III study of capecitabine plus oxaliplatin compared with fluorouracil/folinic acid plus oxaliplatin as first-line therapy for metastatic colorectal cancer. J Clin Oncol 26: 2006-2012, 2008.

250. Skof E, Rebersek M, Hlebanja $\mathrm{Z}$ and Ocvirk J: Capecitabine plus irinotecan (XELIRI regimen) compared to 5-FU/LV plus Irinotecan (FOLFIRI regimen) as neoadjuvant treatment for patients with unresectable liver-only metastases of metastatic colorectal cancer: A randomised prospective phase II trial. BMC Cancer 9: 120, 2009.
251. Obrand DI and Gordon PH: Incidence and patterns of recurrence following curative resection for colorectal carcinoma. Dis Colon Rectum 40: 15-24, 1997.

252. Brodsky FM: Monoclonal antibodies as magic bullets. Pharm Res 5: 1-9, 1988

253. Lee YT, Tan YJ and Oon CE: Molecular targeted therapy: Treating cancer with specificity. Eur J Pharmacol 834: 188-196, 2018.

254. Martinelli E, Ciardiello D, Martini G, Troiani T, Cardone C, Vitiello PP, Normanno N, Rachiglio AM, Maiello E, Latiano $\mathrm{T}$, et al: Implementing anti-epidermal growth factor receptor (EGFR) therapy in metastatic colorectal cancer: Challenges and future perspectives. Ann Oncol 31: 30-40, 2020.

255. Oh DY and Bang YJ: HER2-targeted therapies-a role beyond breast cancer. Nat Rev Clin Oncol 17: 33-48, 2020.

256. Ferguson FM and Gray NS: Kinase inhibitors: The road ahead. Nat Rev Drug Discov 17: 353-377, 2018.

257. Tariman JD: Changes in cancer treatment: Mabs, Mibs, Mids, Nabs, and Nibs. Nurs Clin North Am 52: 65-81, 2017.

258. André T, Blons H, Mabro M, Chibaudel B, Bachet JB, Tournigand $\mathrm{C}$, Bennamoun $\mathrm{M}$, Artru $\mathrm{P}$, Nguyen $\mathrm{S}$, Ebenezer C, et al: Panitumumab combined with irinotecan for patients with KRAS wild-type metastatic colorectal cancer refractory to standard chemotherapy: A GERCOR efficacy, tolerance, and translational molecular study. Ann Oncol 24: 412-419, 2013

259. Papadatos-Pastos D, Rabbie R, Ross P and Sarker D: The role of the PI3K pathway in colorectal cancer. Crit Rev Oncol Hematol 94: 18-30, 2015.

260. Katz LH, Li Y, Chen JS, Muñoz NM, Majumdar A, Chen J and Mishra L: Targeting TGF- $\beta$ signaling in cancer. Expert Opin Ther Targets 17: 743-760, 2013.

261. Jin D, Fang Y, Li Z, Chen Z and Xiang J: Epithelial-mesenchymal transition-associated microRNAs in colorectal cancer and drug-targeted therapies (Review). Oncol Rep 33: 515-525, 2015.

262. Qiao L and Wong BC: Role of Notch signaling in colorectal cancer. Carcinogenesis 30: 1979-1986, 2009.

263. Katoh M and Katoh M: Precision medicine for human cancers with Notch signaling dysregulation (Review). Int J Mol Med 45: 279-297, 2020.

264. Fragoulis GE, Mclnnes IB and Siebert S: JAK-inhibitors. New players in the field of immune-mediated diseases beyond rheumatoid arthritis. Rheumatology (Oxford) 58 (Suppl 1), i42-i54, 2019.

265. Wang SW, Hu J, Guo QH, Zhao Y, Cheng JJ, Zhang DS, Fei Q, Li J and Sun YM: AZD1480, a JAK inhibitor, inhibits cell growth and survival of colorectal cancer via modulating the JAK2/STAT3 signaling pathway. Oncol Rep 32: 1991-1998, 2014.

266. Gulino A, Ferretti E and De Smaele E: Hedgehog signalling in colon cancer and stem cells. EMBO Mol Med 1: 300-302, 2009.

267. Wu JY, Xu XF, Xu L, Niu PQ, Wang F, Hu GY, Wang XP and Guo CY: Cyclopamine blocked the growth of colorectal cancer SW116 cells by modulating some target genes of Gli1 in vitro. Hepatogastroenterology 58: 1511-1518, 2011.

268. Varnat F, Duquet A, Malerba M, Zbinden M, Mas C, Gervaz P and Ruiz i Altaba A: Human colon cancer epithelial cells harbour active HEDGEHOG-GLI signalling that is essential for tumour growth, recurrence, metastasis and stem cell survival and expansion. EMBO Mol Med 1: 338-351, 2009.

269. Gonzalez-Donquiles C, Alonso-Molero J, Fernandez-Villa T, Vilorio-Marqués L, Molina AJ and Martín V: The NRF2 transcription factor plays a dual role in colorectal cancer: A systematic review. PLoS One 12: e0177549, 2017.

270. Wu WK, Wang XJ, Cheng AS, Luo MX, Ng SS, To KF, Chan FK, Cho CH, Sung JJ and Yu J: Dysregulation and crosstalk of cellular signaling pathways in colon carcinogenesis. Crit Rev Oncol Hematol 86: 251-277, 2013.

271. Hurwitz H, Fehrenbacher L, Novotny W, Cartwright T, Hainsworth J, Heim W, Berlin J, Baron A, Griffing S, Holmgren $\mathrm{E}$, et al: Bevacizumab plus irinotecan, fluorouracil, and leucovorin for metastatic colorectal cancer. N Engl J Med 350: 2335-2342, 2004.

272. Passardi A, Nanni O, Tassinari D, Turci D, Cavanna L, Fontana A, Ruscelli S, Mucciarini C, Lorusso V, Ragazzini A, et al: Effectiveness of bevacizumab added to standard chemotherapy in metastatic colorectal cancer: Final results for first-line treatment from the ITACa randomized clinical trial. Ann Oncol 26: 1201-1207, 2015. 
273. Tang PA, Cohen SJ, Kollmannsberger C, Bjarnason G, Virik K, MacKenzie MJ, Lourenco L, Wang L, Chen A and Moore MJ: Phase II clinical and pharmacokinetic study of aflibercept in patients with previously treated metastatic colorectal cancer. Clin Cancer Res 18: 6023-6031, 2012.

274. Van Cutsem E, Sobrero AF, Siena S, Falcone A, Ychou M, Humblet Y, Bouche O, Mineur L, Barone C, Adenis A, et al Phase III CORRECT trial of regorafenib in metastatic colorectal cancer (mCRC). J Clin Oncol 30 (15 Suppl): S3502, 2012.

275. Tabernero J, Yoshino T, Cohn AL, Obermannova R, Bodoky G, Garcia-Carbonero R, Ciuleanu TE, Portnoy DC, Van Cutsem E, Grothey A, et al: Ramucirumab versus placebo in combination with second-line FOLFIRI in patients with metastatic colorectal carcinoma that progressed during or after first-line therapy with bevacizumab, oxaliplatin, and a fluoropyrimidine (RAISE): A randomised, double-blind, multicentre, phase 3 study. Lancet Oncol 16: 499-508, 2015.

276. Bendell JC, Ervin TJ, Gallinson D, Singh J, Wallace JA, Saleh MN, Vallone M, Phan SC and Hack SP: Treatment rationale and study design for a randomized, double-blind, placebo-controlled phase II study evaluating onartuzumab (MetMAb) in combination with bevacizumab plus mFOLFOX-6 in patients with previously untreated metastatic colorectal cancer. Clin Colorectal Cancer 12: 218-222, 2013.

277. Shao Z, Pan H, Tu S, Zhang J, Yan S and Shao A: HGF/c-Met axis: The advanced development in digestive system cancer. Front Cell Dev Biol 8: 801, 2020.

278. Ganesh K, Stadler ZK, Cercek A, Mendelsohn RB, Shia J, Segal NH and Diaz LA Jr: Immunotherapy in colorectal cancer: Rationale, challenges and potential. Nat Rev Gastroenterol Hepatol 16: 361-375, 2019.

279. Passardi A, Canale M, Valgiusti $M$ and Ulivi P: Immune checkpoints as a target for colorectal cancer treatment. Int J Mol Sci 18: 1324, 2017.

280. Brahmer JR, Tykodi SS, Chow LQ, Hwu WJ, Topalian SL, Hwu P, Drake CG, Camacho LH, Kauh J, Odunsi K, et al: Safety and activity of anti-PD-L1 antibody in patients with advanced cancer. N Engl J Med 366: 2455-2465, 2012.
281. Giannakis M, Mu XJ, Shukla SA, Qian ZR, Cohen O,Nishihara R, Bahl S, Cao Y, Amin-Mansour A, Yamauchi M, et al: Genomic correlates of immune-cell infiltrates in colorectal carcinoma. Cell Rep 15: 857-865, 2016.

282. Llosa NJ, Cruise M, Tam A, Wicks EC, Hechenbleikner EM, Taube JM, Blosser RL, Fan H, Wang H, Luber BS, et al: The vigorous immune microenvironment of microsatellite instable colon cancer is balanced by multiple counter-inhibitory checkpoints. Cancer Discov 5: 43-51, 2015.

283. Le DT, Uram JN, Wang H, Bartlett BR, Kemberling H, Eyring AD, Skora AD, Luber BS, Azad NS, Laheru D, et al: PD-1 blockade in tumors with mismatch-repair deficiency. N Engl J Med 372: 2509-2520, 2015.

284. Marcus L, Lemery SJ, Keegan P and Pazdur R: FDA approval summary: Pembrolizumab for the treatment of microsatellite instability-high solid tumors. Clin Can Res 25, 3753-3758, 2019.

285. Andre T, Shiu KK, Kim TW, Jensen BV, Jensen LH, Punt CJA, Smith DM, Garcia-Carbonero R, Benavides M, Gibbs P, et al: Pembrolizumab vs chemotherapy for microsatellite instability-high/mismatch repair deficient metastatic colorectal cancer: The phase 3 KEYNOTE-177 study. J Clin Oncol 38 (18 Suppl): LBA4, 2020.

286. U.S. Food and Drug (FDA): FDA grants nivolumab accelerated approval for MSI-H or dMMR colorectal cancer. FDA, Silver Spring, MD, 2017. https://www.fda.gov/drugs/ resources-information-approved-drugs/fda-grants-nivolumab-accelerated-approval-msi-h-or-dmmr-colorectal-cancer. Accessed January 8,2017.

287. Sun J, Zheng Y, Mamun M, Li X, Chen X and Gao Y: Research progress of PD-1/PD-L1 immunotherapy in gastrointestinal tumors. Biomed Pharmacother 129, 110504, 2020.

This work is licensed under a Creative Commons Attribution-NonCommercial-NoDerivatives 4.0 International (CC BY-NC-ND 4.0) License. 